\title{
Iniciación a la curación de contenidos en la universidad: una experiencia en el área de psicobiología.
}

\author{
Introduction to Content Curation in the University. An Experience in the \\ Psychobiology Area \\ $\mathrm{M}^{\mathrm{a}}$ José Romero Tirado \\ Universidad de Huelva. España. \\ mariajose.romero@dpces.uhu.es
}

\begin{abstract}
Resumen
En este artículo exponemos una experiencia de curación de contenidos realizada en la asignatura Psicobiología Sistémica de segundo del Grado de Psicología en la Universidad de Huelva.

La estrategia implementada se ha validado a través de un cuestionario cumplimentado por los alumnos y alumnas, así como los docentes participantes. Los resultados reflejan que la curación de contenidos como estrategia didáctica es apropiada y avala la necesidad de asumir planteamientos didácticos orientados a mejorar la competencia informacional de los estudiantes universitarios entre otras competencias.
\end{abstract}

\section{Palabras clave}

Curación de contenidos, filtrado, aprendizaje/trabajo colaborativo, entornos personales de aprendizaje (EPA).

\begin{abstract}
We present in this report an experience of curation contents, which is done in systemic psychobiology area subject, in second level in the Huelva University.

The implemented strategy has been validated through a questionnaire completed by the students and participants teachers as well. The results show that the curation contents as teaching strategy is relevant and indeed to assume teaching approaches aimed to improve the students' competence information and other subjects.
\end{abstract}

\section{Key words}

Content curation, filtering, collaborative learning, personal learning environments.

\section{Introducción}

"Vamos a enseñarles a utilizar las fuentes de información y también a cuestionarlas"

(Howard Gardner).

Como afirma Cornellá (2008) en la sociedad actual vivimos inmersos en el acceso rápido a la información con distintas representaciones y formatos que son de fácil acceso y que se traduce en una sobresaturación de la información que resulta difícil clarificar y que se ha tornado en acuñar con el término de infoxicación. La sociedad del conocimiento demanda otras formas de entender, gestionar y manejar la información que implican un cambio a nivel metodológico, planteándose la necesidad de desarrollar 
en el alumnado distintas tipologías de conocimientos y habilidades para actuar de forma competente (Badía, 2006). En las habilidades universitarias de Marcelo, (2001) se plantean tres grupos de habilidades que todo estudiante universitario debe adquirir. A saber: competencias académicas (buscar, localizar, leer, anotar, representar gráficamente, escribir, comunicar, etc.); competencias de investigación (observar, recoger información, realizar hipótesis, presentar datos y valorar) y competencias sociales (colaborar, discutir, trabajar en equipo y resolver conflictos).

Por otro lado, asistimos en la actualidad a un incremento de la demanda de competencias clave a nivel laboral, como el trabajo colaborativo y la gestión de la información en lugares ubicuos y asincrónicos, razón por la cual se hace indispensable la formación en dichas competencias en todos los niveles educativos y, especialmente en la educación superior (Negre, Marín \& Pérez Garcías, 2013).

Las TICs suelen estar diseñadas para formar representaciones escritas y visuales que medien en la construcción colaborativa del conocimiento en entornos virtuales y asincrónicos. En los entornos abiertos de aprendizaje fundamentados en la tecnología según Badía (2006), implican que los alumnos y alumnas sean los propios actores de su aprendizaje, tomando decisiones en la planificación y desarrollo del mismo, gestionando el tiempo, la forma de acceder y trabajar con los diferentes recursos y contenidos, reajustando los planes o estrategias iniciados anteriormente, entre otros aspectos. En este sentido, el alumnado es responsable activo de su aprendizaje e indirectamente también del de sus compañeros y compañeras, aprendiendo a hacer mientras construye su conocimiento desde el constructivismo más tradicional. La ANECA (2003) incluye entre las competencias básicas de la educación superior, la importancia del trabajo colaborativo en el proceso de aprendizaje y se incluye también en el actual marco de convergencia europeo, dentro del proyecto Tuning Educational Structures in Europe (González \& Wagenaar, 2003).

La comunidad universitaria ha de implicarse activamente con esta necesidad motivada principalmente por el impulso y perfeccionamiento de las TIC, así como por la necesidad de entender e incorporar dichas tecnologías a nivel educativo (Marín, Moreno \& Negre, 2012).

Siguiendo a González (2012), la curación de contenidos, como metodología didáctica, ha de realizarse al servicio de las TIC facilitando el aprendizaje activo, la creación, la colaboración y la comunicación. Los usos de las TIC proporcionaran un valor añadido en la innovación docente universitaria y producirán cambios importantes en las distintas formas en las que, el profesorado y alumnado de la educación superior interactúe, fuera y dentro del aula y, por ende en la forma de aprender y enseñar (Onrubia, 2007).

La competencia informacional se relaciona íntimamente con la curación de contenidos, que atendiendo a la definición de Digital Curation Centre (2010), no es más que la agrupación, mantenimiento y conservación de la información encontrada, aportando un valor añadido.

La curación de contenidos supone una actualización permanente, obligando al curador de contenidos a actualizarse constantemente en la gestión de su propio aprendizaje, aprendiendo a aprender (De Benito, Darder, Lizana, Marín, Moreno \& Salinas, 2013). Por ello, la incorporación de las TIC y la sociedad del conocimiento exigen un cambio

Iniciación a la curación de contenidos en la universidad: una experiencia en el área de psicobiología. María José Romero Tirado. 
urgente en el rol docente ejerciendo más como un guía y facilitador de los recursos que contenedor del conocimiento (Salinas, 2008).

En este sentido, el alumnado como principal agente activo de su aprendizaje, elabora su propio entorno personal de aprendizaje (PLE), utilizando las herramientas y servicios necesarios para aprender, incorporando instrumentos y estrategias de selección, filtrado y curación de los contenidos, que le permita gestionar, organizar y compartir la información principal, instaurándose un proceso de aprendizaje autónomo a lo largo del ciclo vital. La agregación, filtrado y curación son tareas clave para ello (De Benito, Darder, Lizana, Marín, Moreno \& Salinas, 2013).

Atendiendo al modelo de curación de contendidos como estrategia didáctica, las fases de la curación de contenido que hemos utilizado son (Negre, Marín \& Pérez Garcías, 2013):

1. Conceptualización: planificar el proceso de curación estableciendo la temática, proponer y acordar con el alumnado el tema del proyecto a desarrollar estableciendo los criterios de formación grupal y de evaluación.

2. Creación y recepción: establecer la creación de metadatos atendiendo a las distintas fuentes para obtener información, búsqueda y filtrado de información (tipo de buscadores, bases de datos, sistemas de curación...)

3. Valoración y selección: valorar la información recogida y seleccionarla atendiendo a aspectos como el rigor de las fuentes. Adecuación a la temática objeto de curación, calidad, cantidad de las fuentes, etc.

4. Conversión, preservación y almacenamiento: transferir la documentación asegurando su almacenamiento siguiendo los estándares establecidos para ello con la consecuente posterior localización.

5. Acceso, uso y reuso de la información garantizando su posterior recuperación.

6. Bhargava, (2011). Transformación: añadir valor a la información curada, agregando, destilando y remezclando principalmente la información original.

El objetivo de esta experiencia educativa es apreciar si la curación de contenidos es valorada positivamente como estrategia didáctica en general y, en el marco de la asignatura, así como discernir si aspectos como la implicación del profesorado influyen positivamente en dicha valoración y conocer el potencial de la curación de contenidos en el ámbito universitario.

\section{Metodología}

El presente estudio, como hemos comentado, se realiza con el objeto de conocer si la curación de contenidos es una estrategia didáctica adecuada a utilizar en el ámbito universitario enmarcada dentro de las nuevas competencias clave de la educación superior. La selección de la muestra fue probabilística accidental y la experiencia didáctica se llevó a cabo al final del primer cuatrismestre del curso 2014-2015, con alumnos que cursaban la asignatura de Psicobiología Sistémica perteneciente a $2^{\circ}$ de grado de Psicología de la Universidad de Huelva. Participaron 3 profesores, encargados de impartir las prácticas de dicha asignatura, y 147 alumnos y alumnas. Solo un alumno

Iniciación a la curación de contenidos en la universidad: una experiencia en el área de psicobiología. 
había tenido contacto previamente con la curación de contenidos y el profesorado implicado tampoco se había enfrentado a dicha tarea, ni a nivel profesional ni didáctico aunque uno de ellos si tenía ligeras nociones al respecto.

Las instrucciones facilitadas al alumnado especificaban la creación de grupos pequeños de 4 a 6 alumnos, así como la necesidad de curar contenidos fuera de las 3 sesiones presenciales de las que constaba la experiencia. Para ello podrían utilizar los recursos y herramientas que considerarán oportunos de los existentes al servicio de la curación de contenidos, insistiéndose en la libertad en la elección de la misma, formato e idioma que, solo estarían supeditados al acuerdo grupal y supervisión del profesorado. Los contenidos obligatoriamente versarían sobre el temario de la asignatura; en este sentido debían guiarse por la guía docente.

La explicación y especificación del procedimiento, características y proceso de evaluación a través de la pertinente rúbrica se acompañaron, además de las oportunas explicaciones verbales, de documentos impresos, disponibles también en la página oficial de la asignatura en Moodle.

Colas, (1992) propone en la investigación educativa, entre otras, como metodología fundamental la entrevista y el cuestionario o escala de actitud. Se planteó la necesidad de usar un cuestionario de evaluación de la actividad, no solo para el alumnado sino también para el profesorado involucrado en la experiencia didáctica al objeto de poder contrastar las similitudes y diferencias entre ambos grupos, adaptados al contexto de la asignatura abarcando aspectos relativos al proceso de aprendizaje, motivación y grado de satisfacción, curriculares, técnicos y funcionales, (Morales, García, Barrón \& Gil, 2007). Para realizar la selección de los ítems se efectuó una encuesta base (Morales 2007) adaptada al contexto y los contenidos. Primero se revisó por tres profesores, dos del Departamento de Pedagogía y uno de los participantes en la actividad. Posteriormente se les consultó a 20 alumnos universitarios al objeto de delimitar si existían problemas en la compresión de ítems. Una vez realizadas las correcciones oportunas se determinó la versión final.

Los cuestionarios administrados (ver Anexo) constan de 42 ítems, con un formato de respuesta tipo Likert con 5 opciones de respuesta ((1) Totalmente en desacuerdo; (2) En desacuerdo; (3) Ni de acuerdo ni en desacuerdo; (4) De acuerdo; (5) Totalmente de acuerdo.), de los cuales solo se utilizaron para este trabajo, 33 ítems por exceder a las pretensiones finales del mismo. Además se añadieron 3 preguntas abiertas al objeto de recabar información más amplia. Los cuestionarios fueron contestados por 147 alumnos y alumnas, mientras que el cuestionario utilizado con los profesores y profesoras fue contestado por los 3 profesores. Hay que destacar que solo el profesor 3 conocía en qué consistía la curación de contenidos y, ninguno de ellos había realizado anteriormente curación de contenidos.

Los criterios utilizados para la agrupación de ítems en categorías con el alumnado y los ítems asociados del cuestionario fueron los siguientes:

Iniciación a la curación de contenidos en la universidad: una experiencia en el área de psicobiología. María José Romero Tirado. 
- VALORACIÓN GENERAL (valoración general de la actividad):

- Pienso que es una práctica motivadora en general (2)

- Valoro de forma positiva la realización de esta práctica en general (16)

- Considero la curación de contenidos como una herramienta efectiva de gestión de mi aprendizaje (20)

- Recomendaría la curación de contenidos a otras personas (21)

- En general creo que la iniciación en la curación de contenidos es altamente satisfactoria (41)

- El esfuerzo y el tiempo dedicado a la curación de contenidos me parece adecuado para los resultados obtenidos (29)

- Pienso que la curación de contenidos es buen recurso para gestionar los contendidos de aprendizaje (32)

- Si de mí dependiera, incorporaría al currículum esta actividad (24)

- Este tipo de actividades se ajusta más a la realidad social que las actividades tradicionales (35)

VALORACIÓN PARTICULAR (valoración de la actividad en el marco de la asignatura):

- La curación de contenidos ha sido significativa para el aprendizaje en el área de Psicobiología (10)

- El tiempo que he dedicado a la curación de contenidos se adecua y es compatible con la asignatura (9)

- Esta experiencia ha mejorado mi interés por la asignatura (25)

- Soy capaz de determinar la relevancia y fiabilidad de la información contenida en Internet en el área de Psicobiología (31)

IMPLICACIÓN DEL PROFESORADO (importancia de la implicación del profesorado y rol docente en la realización de la actividad ):

- El profesorado se ha encargado de instruir y dinamizar la actividad (3)

- El profesorado implicado desconoce en qué consiste la curación de contenidos (17) El pro

- fesorado no se ha implicado en el desarrollo de la actividad (19)

- El desarrollo de las sesiones ha supuesto un cambio positivo en el rol del docente (39) 
METODOLOGÍA (instrucciones de la prácticas, trabajo colaborativo, implicación del alumnado, evaluación de la actividad, conocimientos previos de la curación):

- Las instrucciones publicadas a través de la plataforma virtual son claras y explicitas respecto a la actividad (4)

- Considero que se trata de una actividad muy apropiada para fomentar el trabajo en equipo/colaborativo (1)

- Trabajar de forma colaborativa supone un labor más motivadora que la experiencia individual (26)

- He conseguido aprender de mis compañeros (27)

- Todos los miembros del grupo realizaron contribuciones que fueron interesantes (33)

- He recibido retroalimentación en relación a mi aprendizaje por los miembros de mi grupo (6)

- Admito no haberme implicado en esta actividad por motivos personales o por decisión propia (30)

- Creo que la forma de evaluar la actividad es adecuada (5)

- La evaluación de la actividad a través de una rúbrica favorece positivamente la realización de la misma (22)

- Me parece adecuado y favorable el poder autoevaluar el desempeño de nuestro trabajo (23)

- Ya utilizaba la curación de contenidos antes de la realización de esta práctica (15)

- No conocía absolutamente nada en relación a la curación de contendidos (37)

PROYECCIÓN (competencias digitales, posibilidades de continuar curando contenidos):

- La curación de contendidos me ha permitido progresar en la adquisición de mis competencias digitales (38)

- Dispongo de los recursos tecnológicos suficientes para continuar con la curación de contenidos en otros contextos (12)

Para la agrupación de ítems en categorías con el profesorado, se usaron criterios similares a los utilizados con el alumnado, aunque obviamente no se incluyeron los mismos ítems: 
VALORACIÓN GENERAL (valoración general de la actividad):

- Pienso que es una práctica motivadora en general (2)

- Creo que la curación de contendidos es un recurso útil a usar en cualquier asignatura en general (8)

- Valoro de forma positiva la realización de esta práctica en general (16)

- Sería interesante que se realizaran más actividades similares en otras asignaturas

- Considero la curación de contenidos como una herramienta efectiva de gestión del aprendizaje(20)

- Recomendaría la curación de contenidos a otras personas (21)

- Esta experiencia ha mejorado mi interés por la docencia en la asignatura (25)

- El esfuerzo y el tiempo dedicado a la curación de contenidos por parte del alumnado, me parece adecuado para los resultados obtenidos (29)

- Pienso que la curación de contenidos es buen recurso para gestionar los contendidos de aprendizaje (32)

- Este tipo de actividades se ajusta más a la realidad social que las actividades tradicionales (35)

- Esta actividad ha conseguido que descubra distintas posibilidades educativas de algunas herramientas que usaba con otro fin (36)

- En general creo que la iniciación en la curación de contenidos es altamente satisfactoria (41)

- El tiempo que los alumnos han dedicado a la curación de contenidos se adecua y es compatible con la asignatura (9)

VALORACIÓN PARTICULAR (valoración de la actividad en el marco de la asignatura:

- La curación de contenidos ha sido significativa para el aprendizaje en el área de Psicobiología (10)

- Si de mí dependiera, incorporaría al currículum esta actividad (24)

- El alumnado es capaz de determinar la relevancia y fiabilidad de la información contenida en internet en el área de Psicobiología (31)

- Las instrucciones publicadas a través de la plataforma virtual fueron claras y explicitas respecto a la actividad (4) 
IMPLICACIÓN DEL PROFESORADO (importancia de la implicación del profesorado y rol docente en la realización de la actividad ):

- Se ha encargado de instruir y dinamizar la actividad (3)

- El desarrollo de las sesiones ha supuesto un cambio positivo en el rol del docente (39)

- No me he implicado en el desarrollo de la actividad (19)

- He aprendido en relación a la curación de contenidos de mis compañeros y/o alumnos (27)

- Admito no haberme implicado en esta actividad por motivos personales o por decisión propia (30)

METODOLOGÍA (instrucciones de la prácticas, trabajo colaborativo, implicación del alumnado, evaluación de la actividad, conocimientos previos de la curación):

- Considero que se trata de una actividad muy apropiada para fomentar el trabajo en equipo/colaborativo (1)

- Trabajar de forma colaborativa supone una labor más motivadora que la experiencia individual (26)

- Todos los miembros de los grupos realizaron, en general, contribuciones que fueron interesantes (33)

- Creo que la forma en que se evaluó la actividad es adecuada (5)

- Ya utilizaba la curación de contenidos antes de la realización de esta práctica (15)

- Desconocía en qué consistía la curación de contenidos (17)

- No conocía absolutamente nada en relación a la curación de contendidos (37)

PROYECCIÓN (competencias digitales, posibilidades de continuar curando contenidos):

- Dirigir y fomentar la curación de contendidos me ha permitido progresar en la adquisición de mis competencias digitales (38)

- Dispongo de los recursos tecnológicos suficientes para continuar con la curación de contenidos en otros contextos (12) 
La administración del cuestionario fue presencial y totalmente anónima, teniendo que especificar el alumnado, el nombre del profesor o profesora encargado o encargada de realizar la práctica, el turno (T1, T2, y T3) y grupo reducido al que pertenecían (p1, p2, p3, p4, p5 y p6).

Las instrucciones para el alumnado en el protocolo de administración fueron las siguientes: "Este cuestionario intenta recabar información sobre distintos aspectos relativos al proceso de aprendizaje de la práctica, iniciación a la curación de contenidos en el área de Psicobiología. Con el fin de conocer, mejorar y adaptar dicha actividad, nos gustaría y agradecemos enormemente, que cumplimente el siguiente cuestionario con carácter anónimo y cuya información será tratada de forma confidencial".

\section{Resultados}

Los resultados obtenidos globalmente en los cuestionarios del alumnado expresados en medias se exponen en los gráficos del 1 al 5:

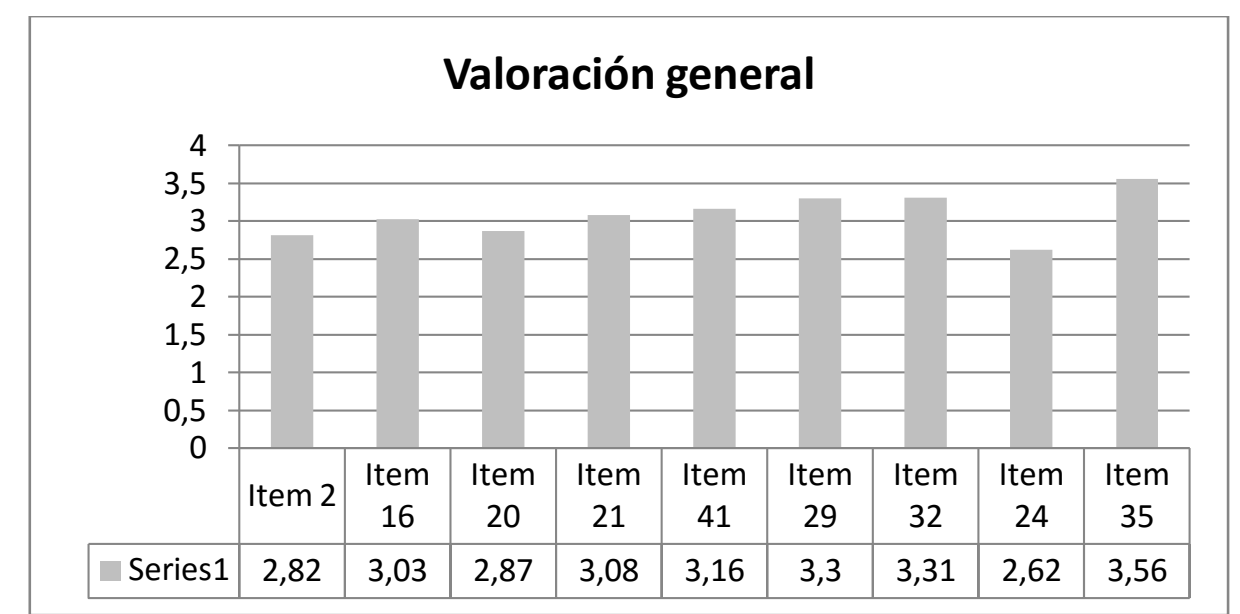

Gráfico 1: Resultados de la categoría Valoración general en el alumnado.

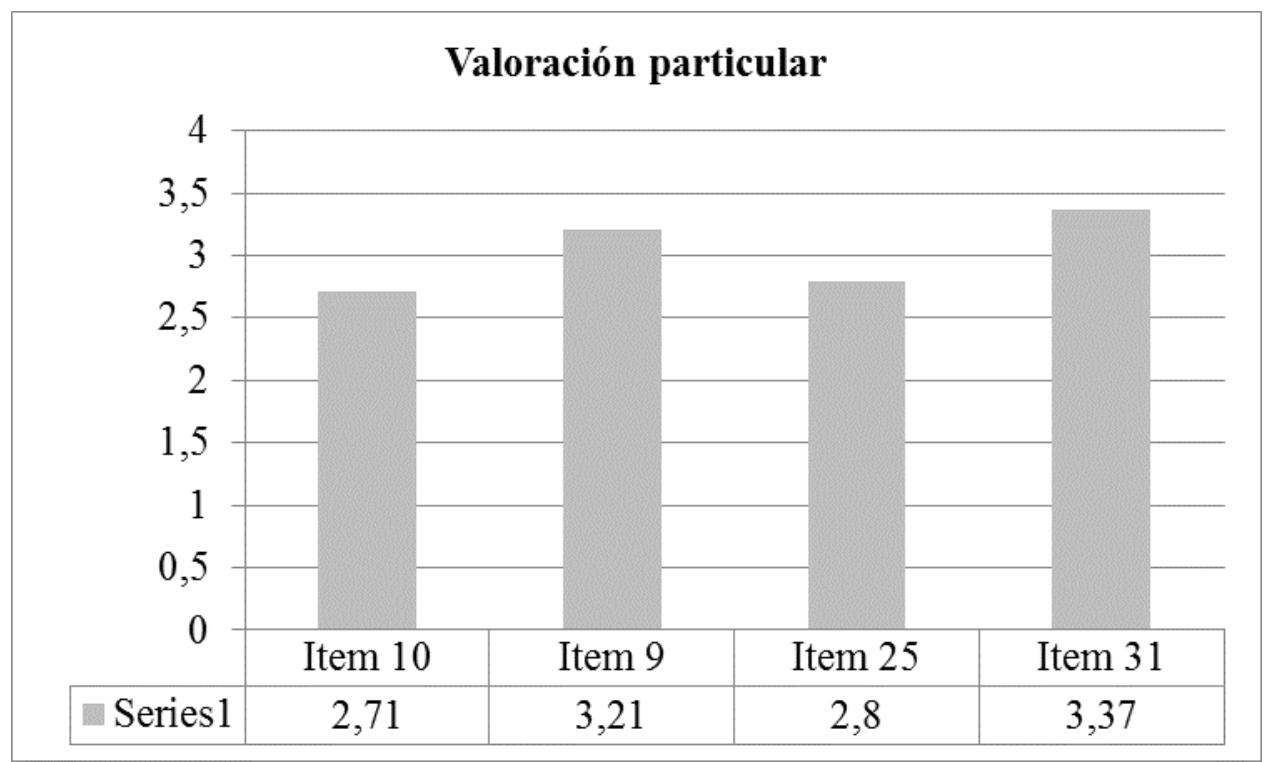

Gráfico 2: Resultados de la categoría Valoración particular en el alumnado.

Iniciación a la curación de contenidos en la universidad: una experiencia en el área de psicobiología. María José Romero Tirado. 


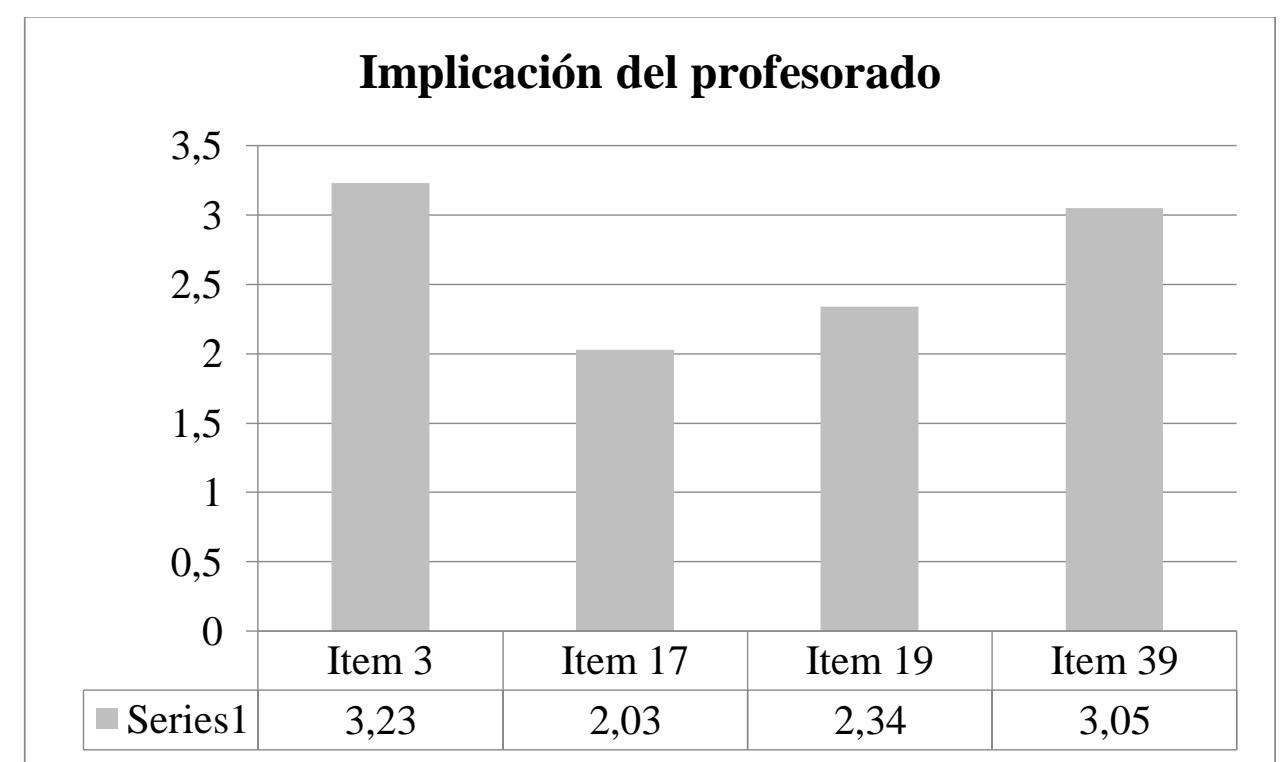

Gráfico 3: Resultados de la categoría Implicación del profesorado en el alumnado.

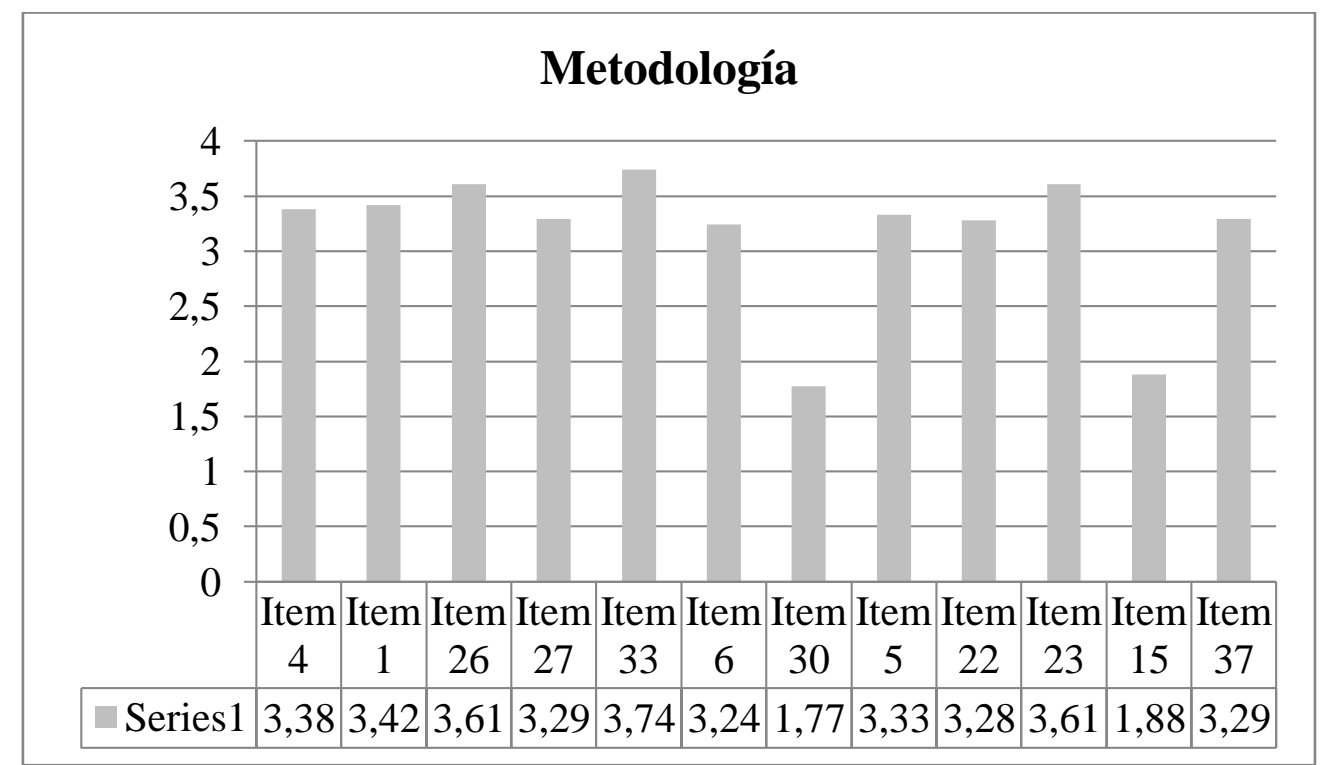

Gráfico 4: Resultados de la categoría Metodología en el alumnado. 


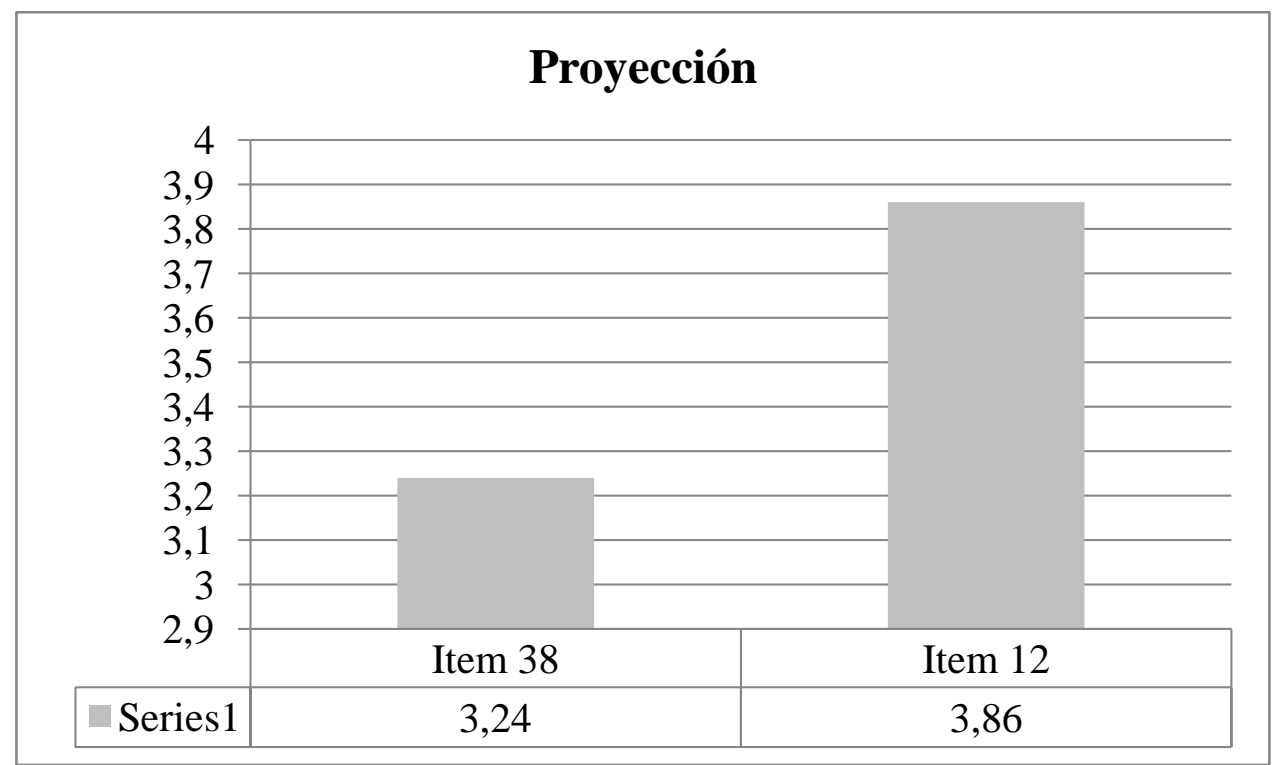

Gráfico 5: Resultados de la categoría Proyección en el alumnado.

En todas las respuestas se consideró cualquier puntuación superior a 2,5 como favorable.

En este sentido, tanto la valoración general como la particular de la curación de contenidos fueron positivas. La implicación del profesorado es considerada efectiva, aunque más de la mitad del alumnado entendió que el profesorado desconocía en qué consistía la curación de contenidos (ítem 17) y no se había implicado en el desarrollo de la actividad (ítem 19). En cuanto a la metodología, la valoración general también fue positiva, si bien muchos de ellos manifestaron no haberse comprometido en esta actividad por motivos personales o por decisión propia (30) y, tampoco utilizaban la curación de contenidos anteriormente (ítem 15). Por otra parte, la curación de contenidos es vista por el alumnado con altas posibilidades de proyección futura.

Los cuestionarios cumplimentados por el profesorado (gráficos 6-10) arrojan los siguientes resultados:

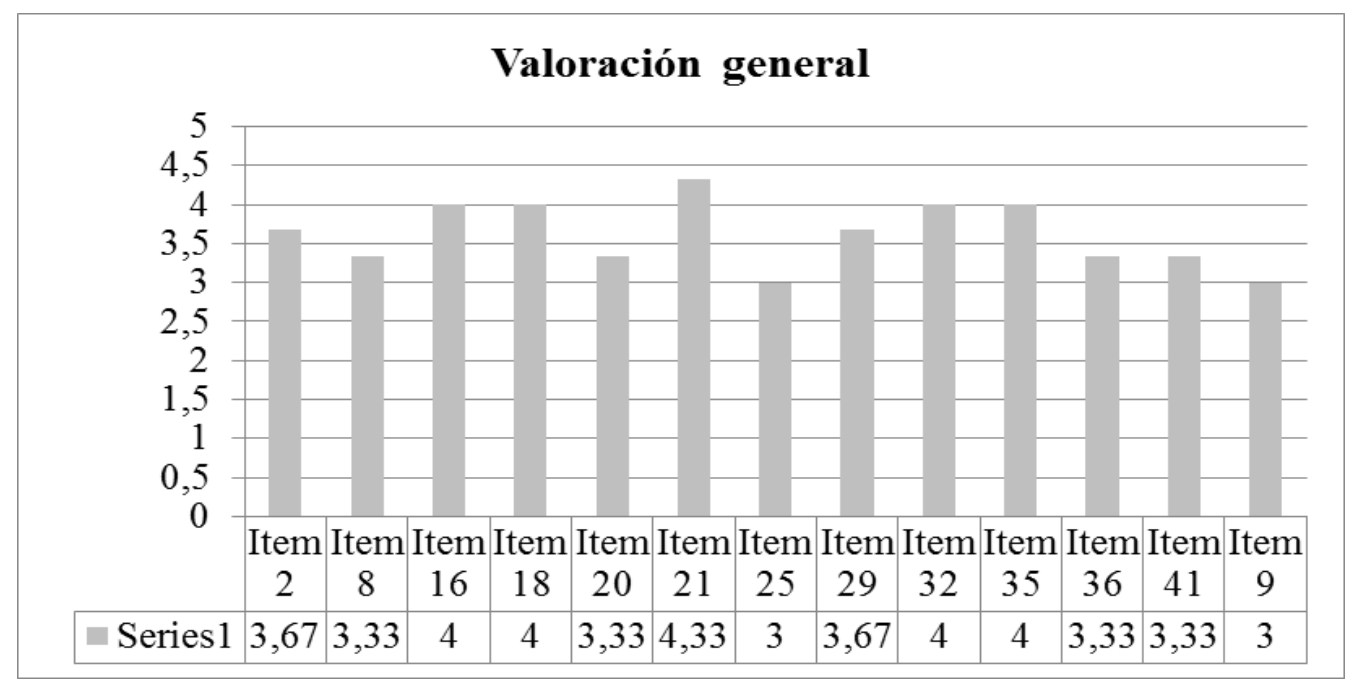

Gráfico 6: Resultados de la categoría Valoración general en el profesorado.

Iniciación a la curación de contenidos en la universidad: una experiencia en el área de psicobiología. María José Romero Tirado. 


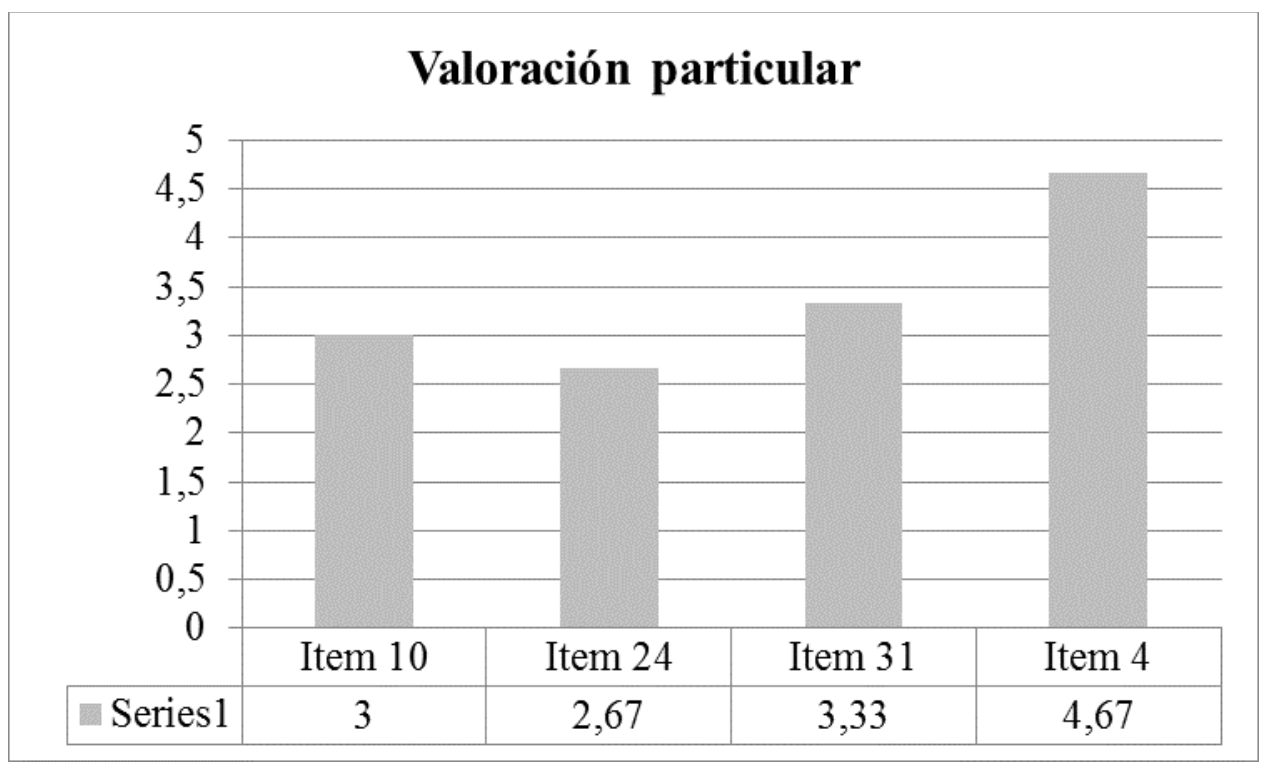

Gráfico 7: Resultados de la categoría Valoración particular en el profesorado.

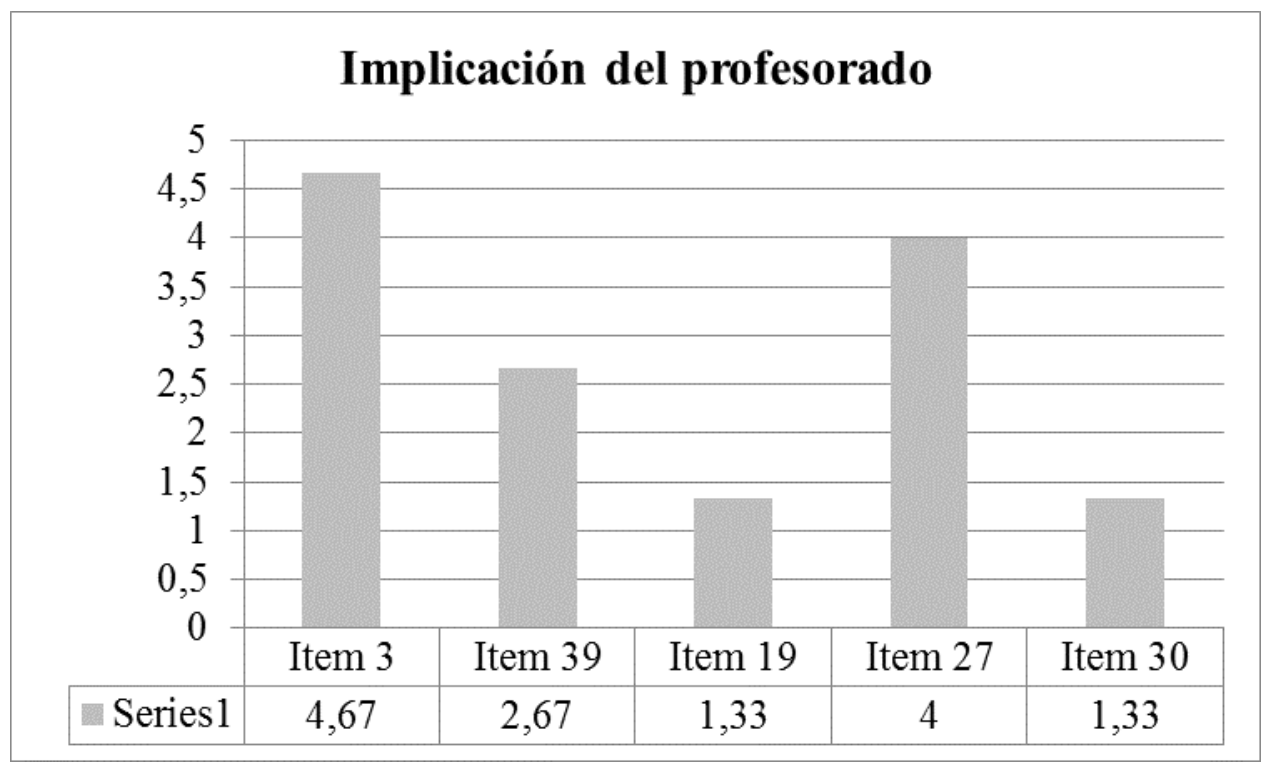

Gráfico 8: Resultados de la categoría Implicación del profesorado en el profesorado. 


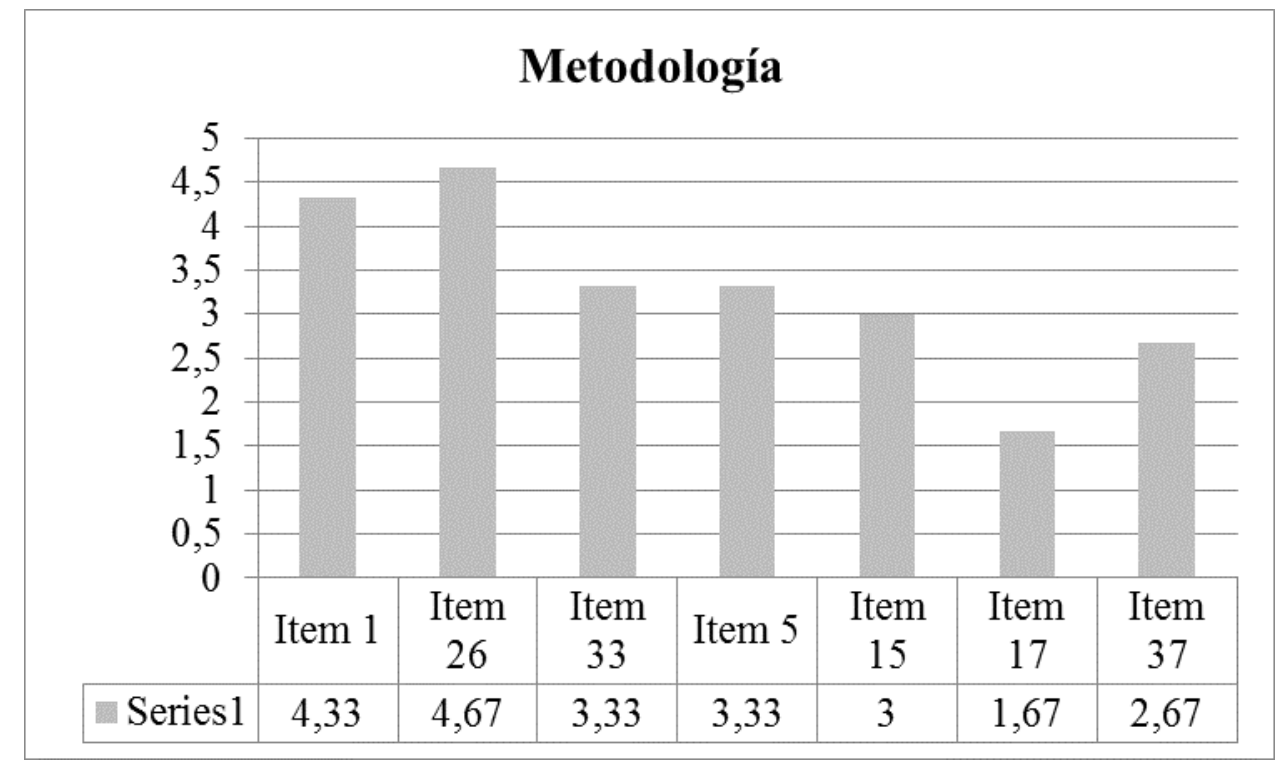

Gráfico 9: Resultados de la categoría Metodología en el profesorado.

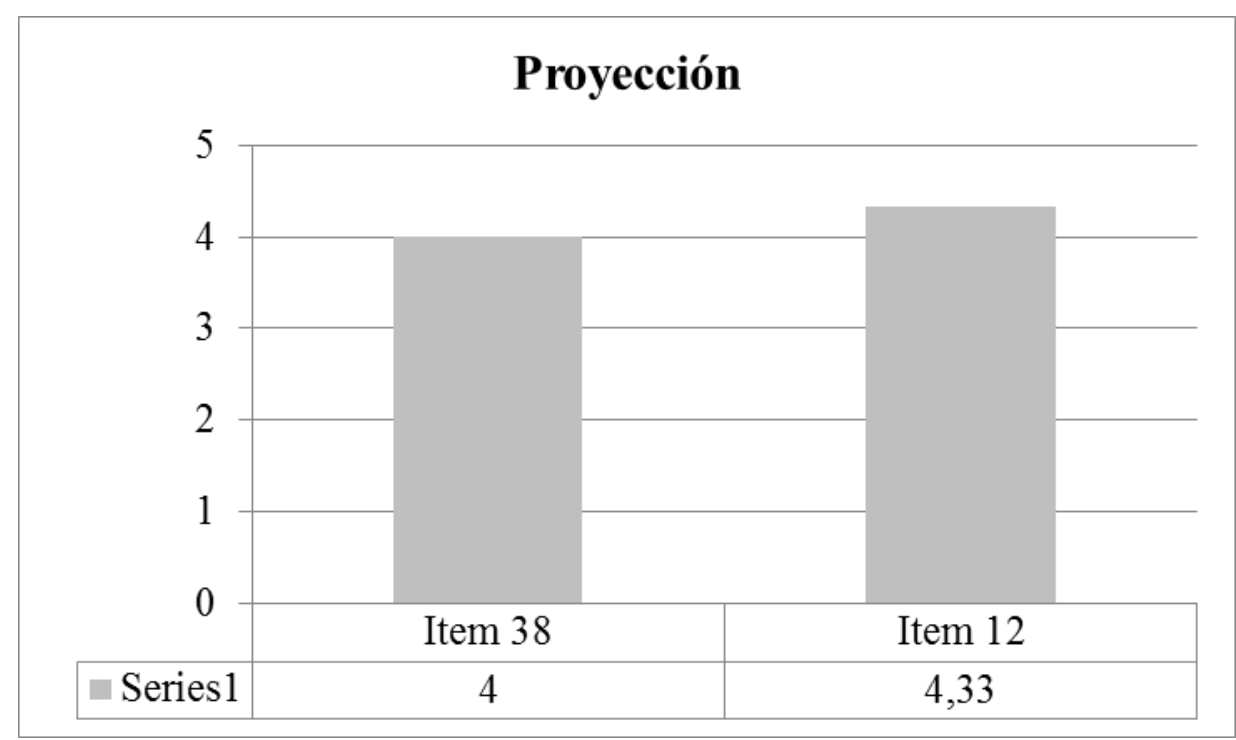

Gráfico 10: Resultados de la categoría Proyección en el profesorado.

El profesorado encargado de dinamizar la curación de contenidos la valora positivamente, tanto de forma general como particular en el contexto de la asignatura. En cuanto a su implicación, consideran haberse involucrado poco en la actividad (ítem 19 y 30). En las categorías de metodología y proyección también es puntuada favorablemente, aunque desconocían en qué consistía la curación de contenidos (ítem 17).

A continuación, en los gráficos del 11 al 15 se muestran los resultados obtenidos por el alumnado en función del grupo en el que realizó la curación de contenidos: 


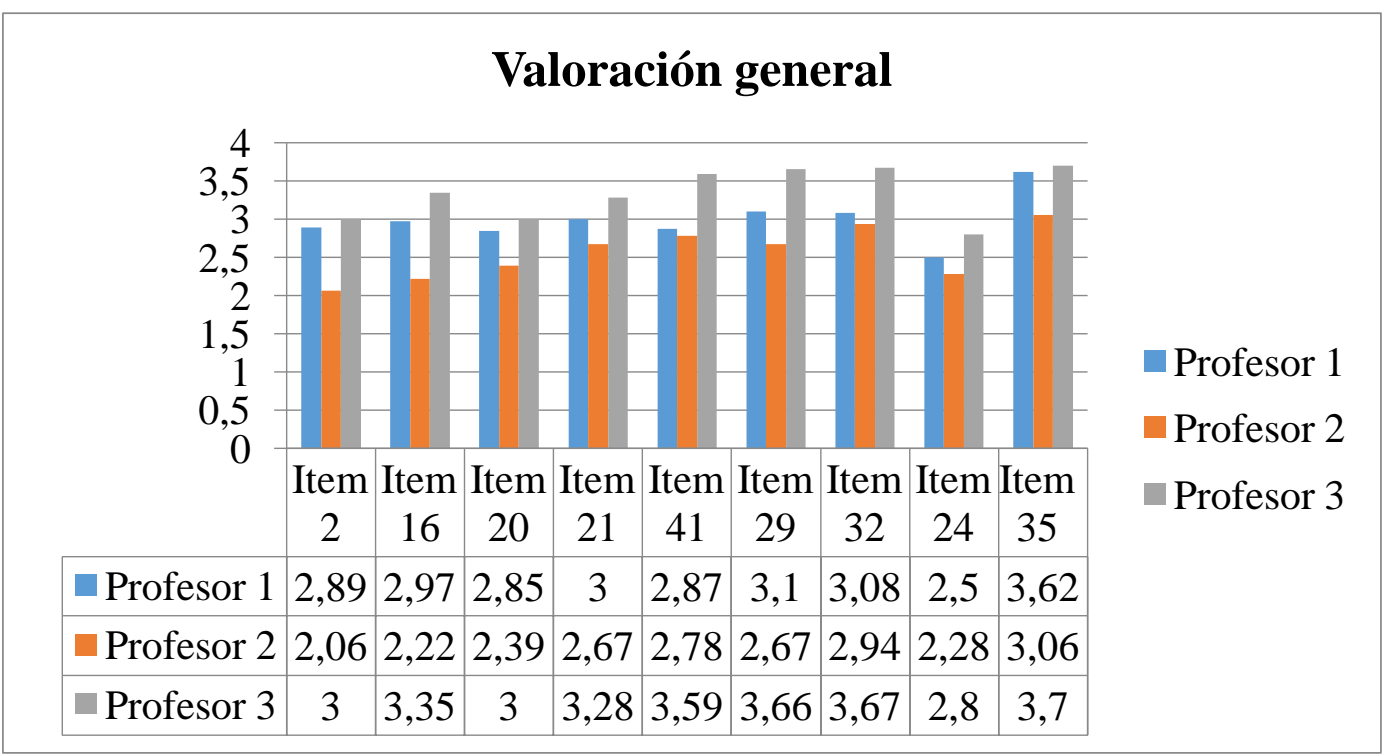

Gráfico 11: Resultados de la categoría Valoración general en el alumnado por grupos.

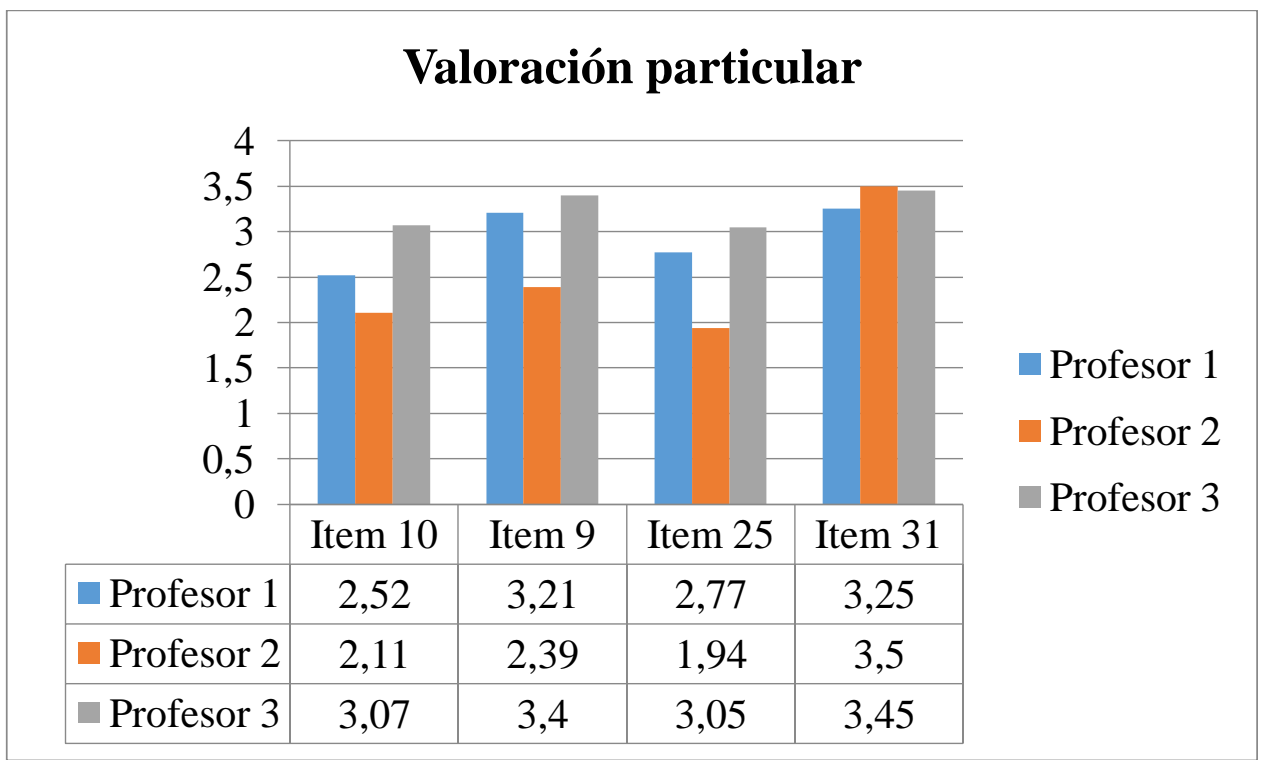

Gráfico 12: Resultados de la categoría Valoración particular general en el alumnado por grupos. 


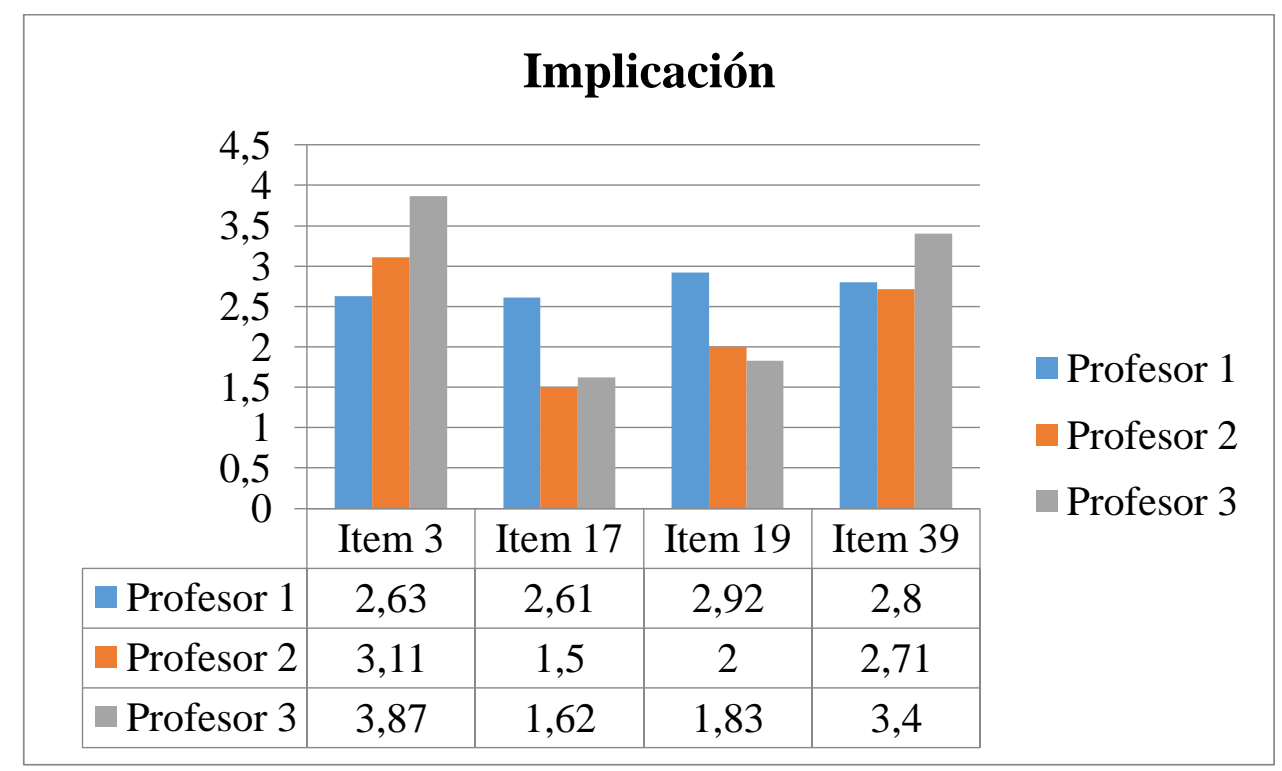

Gráfico 13: Resultados de la categoría Implicación en el alumnado por grupos.

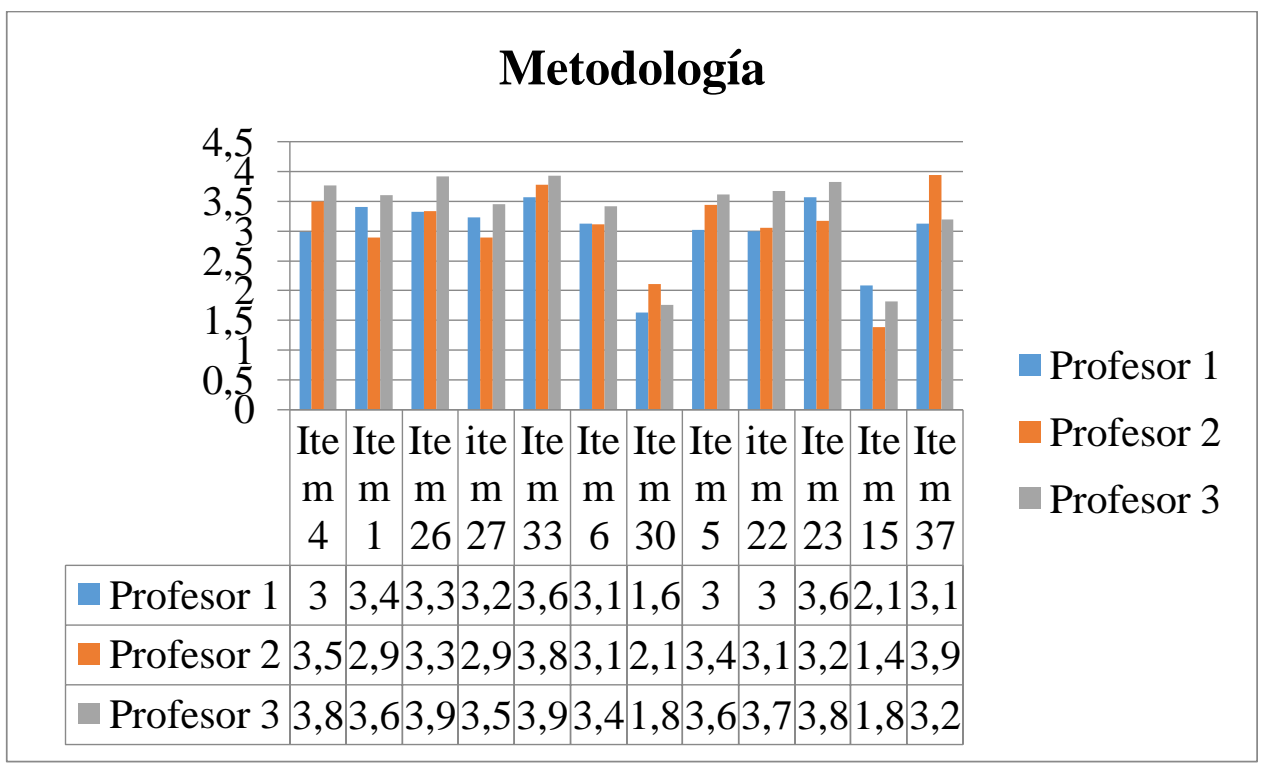

Gráfico 14: Resultados de la categoría Metodología en el alumnado por grupos. 


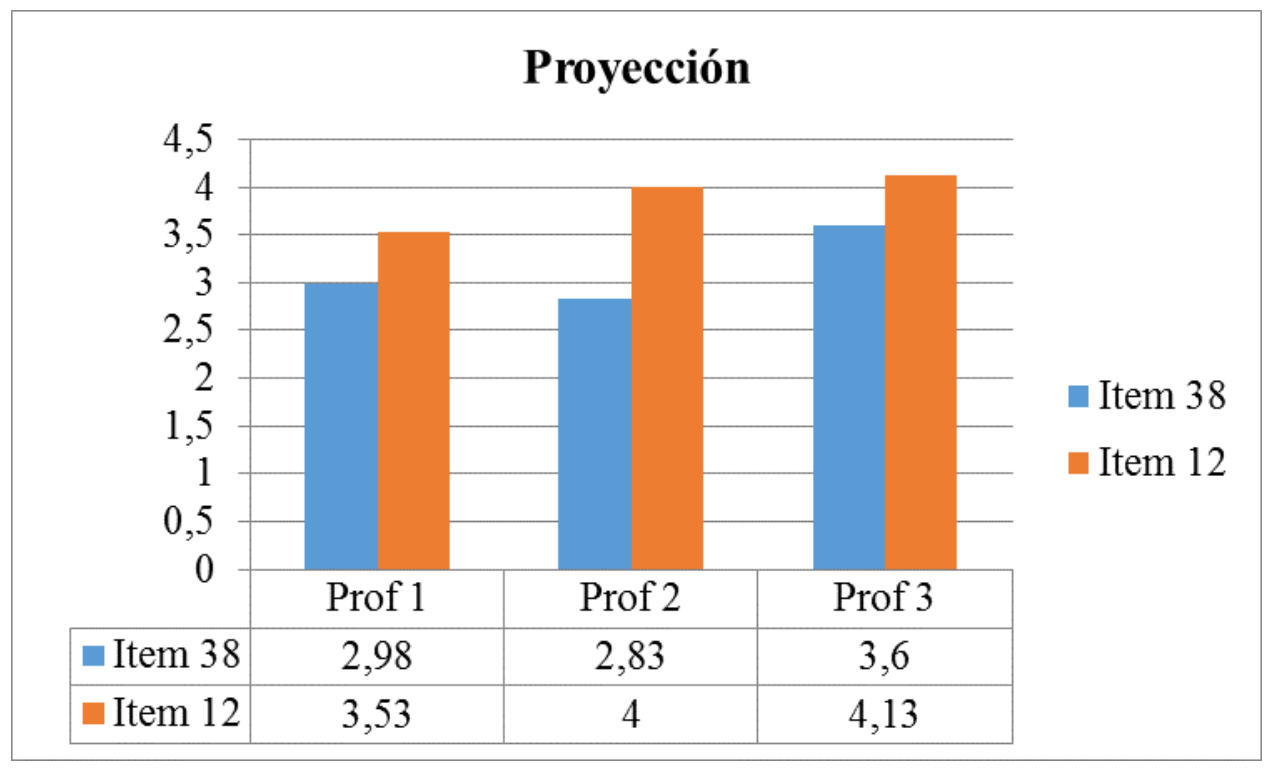

Gráfico 15: Resultados de la categoría Proyección en el alumnado por grupos.

Si observamos los resultados de los alumnos en función de los tres grupos, en su mayoría realizó una valoración general de la actividad positiva, mostrando un mayor grado de satisfacción aquellos que realizaron la curación de contenidos con el profesor 3.

En cuanto a la valoración particular de la actividad, es decir, dentro del marco de la asignatura, los grupos que hicieron la curación de contenidos con los profesores 1 y 3 estimaron positivamente la curación de contenidos dentro del área de Psicobiología, si bien los alumnos que curaron los contenidos con el profesor 2, aunque también lo valoran positivamente, lo hacen menos.

En lo relativo a la implicación del profesorado durante el desarrollo de la curación de contenidos, el alumnado considera que el profesor 3 es el que más se ha implicado y ha mantenido un rol activo durante la actividad.

En relación a los aspectos metodológicos, los tres grupos admiten no haberse implicado lo suficiente en la actividad y manifiestan no haber realizado antes curación de contenidos. Por otra parte, valoraron favorablemente la proyección futura de la curación de contenidos.

Los resultados de los cuestionarios contestados por cada profesor (gráficos 16-20) son: 


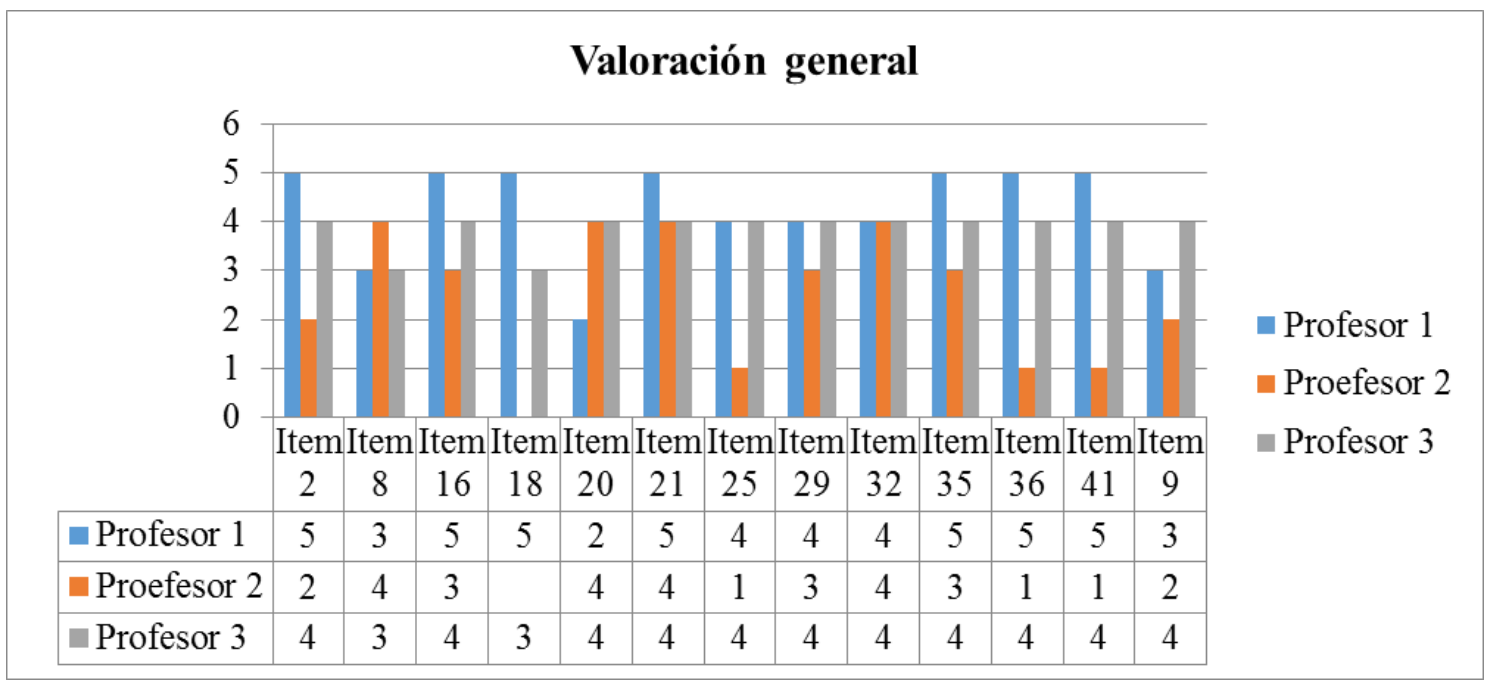

Gráfico 16: Resultados de la categoría Valoración general en el profesorado por profesor.

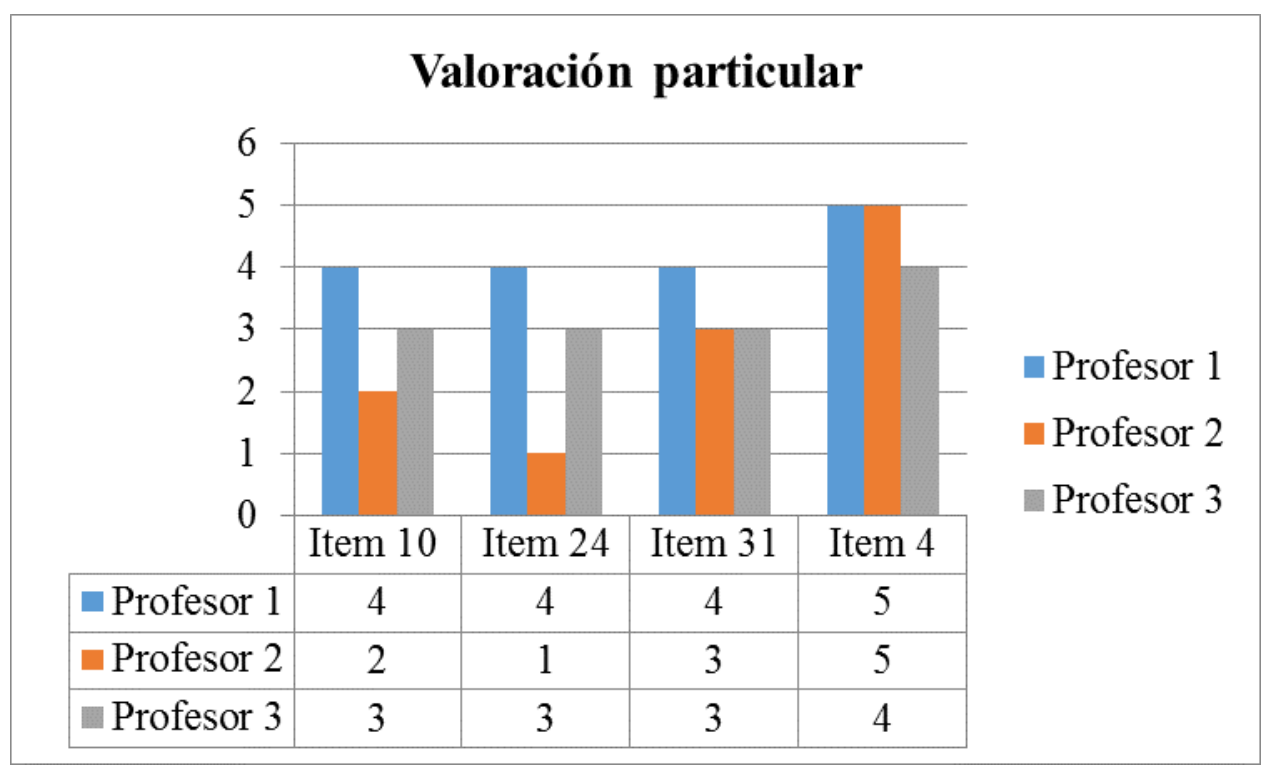

Gráfico 17: Resultados de la categoría Valoración particular en el profesorado por profesor. 


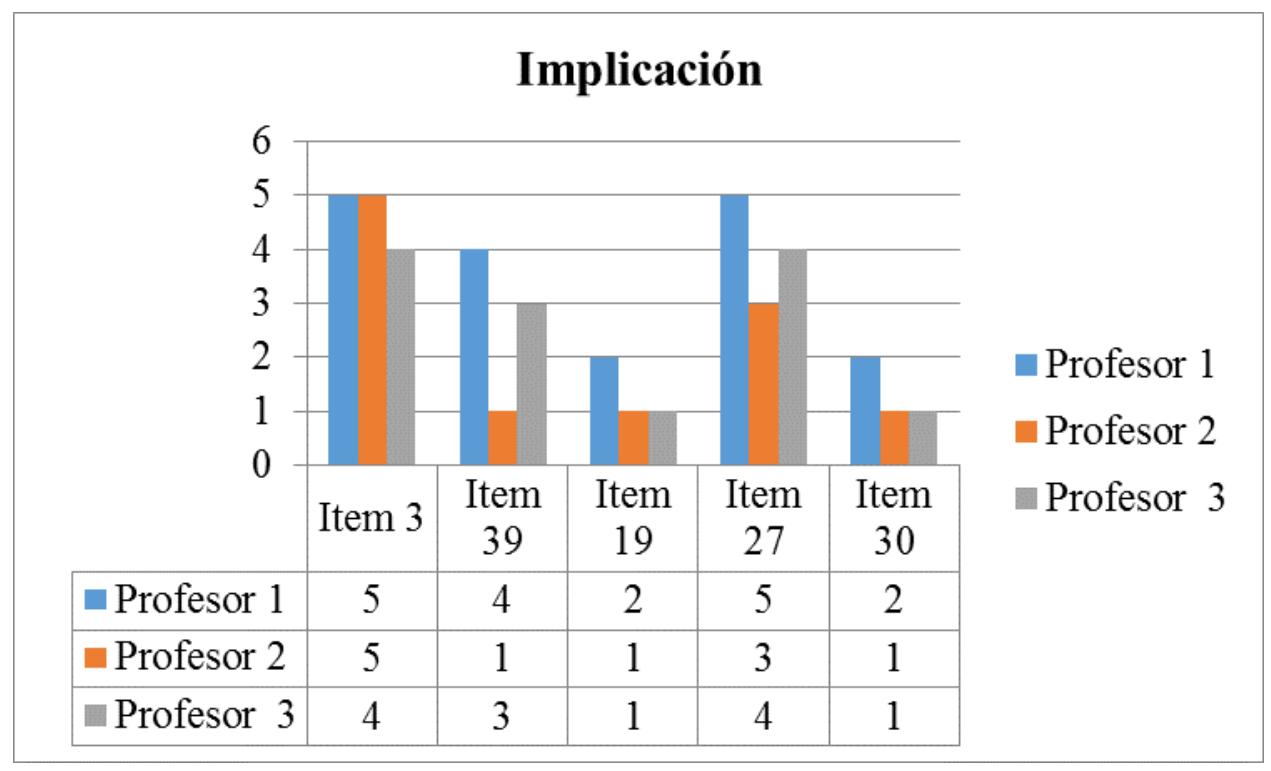

Gráfico 18: Resultados de la categoría Implicación en el profesorado por profesor.

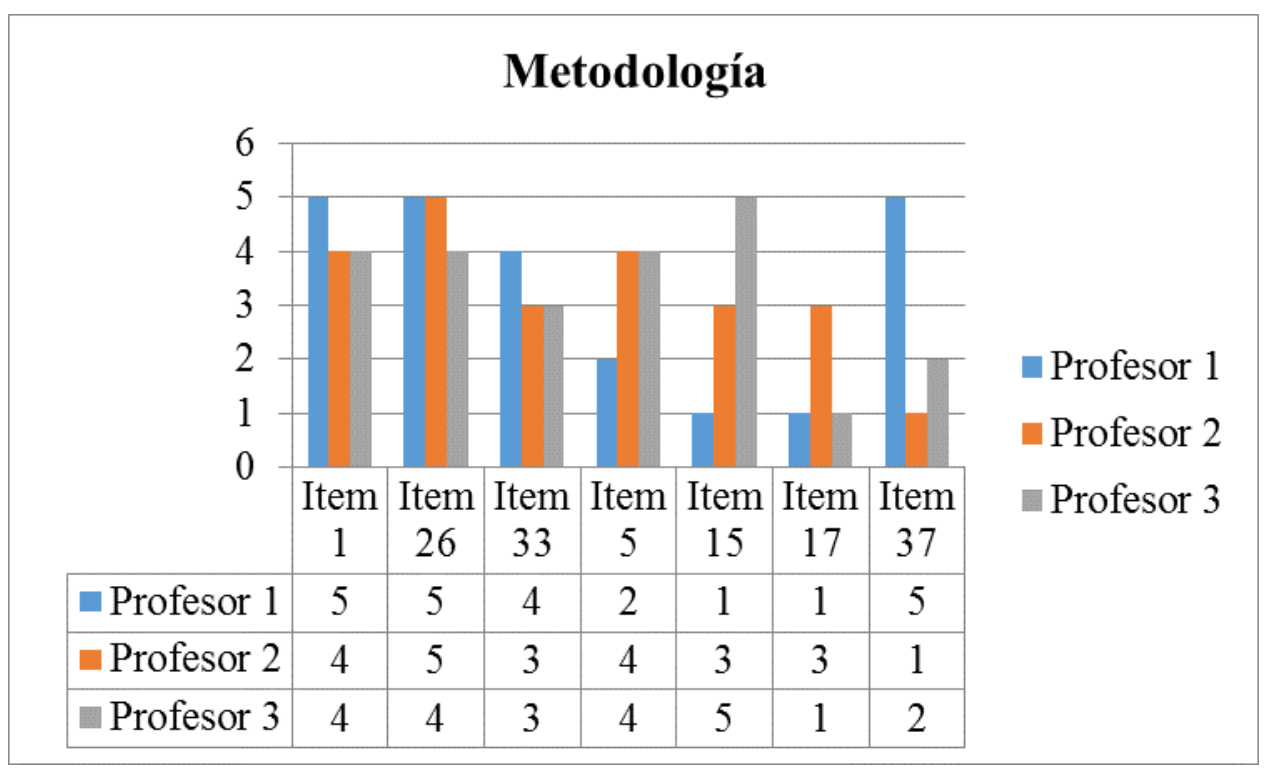

Gráfico 19: Resultados de la categoría Metodología en el profesorado por profesor. 


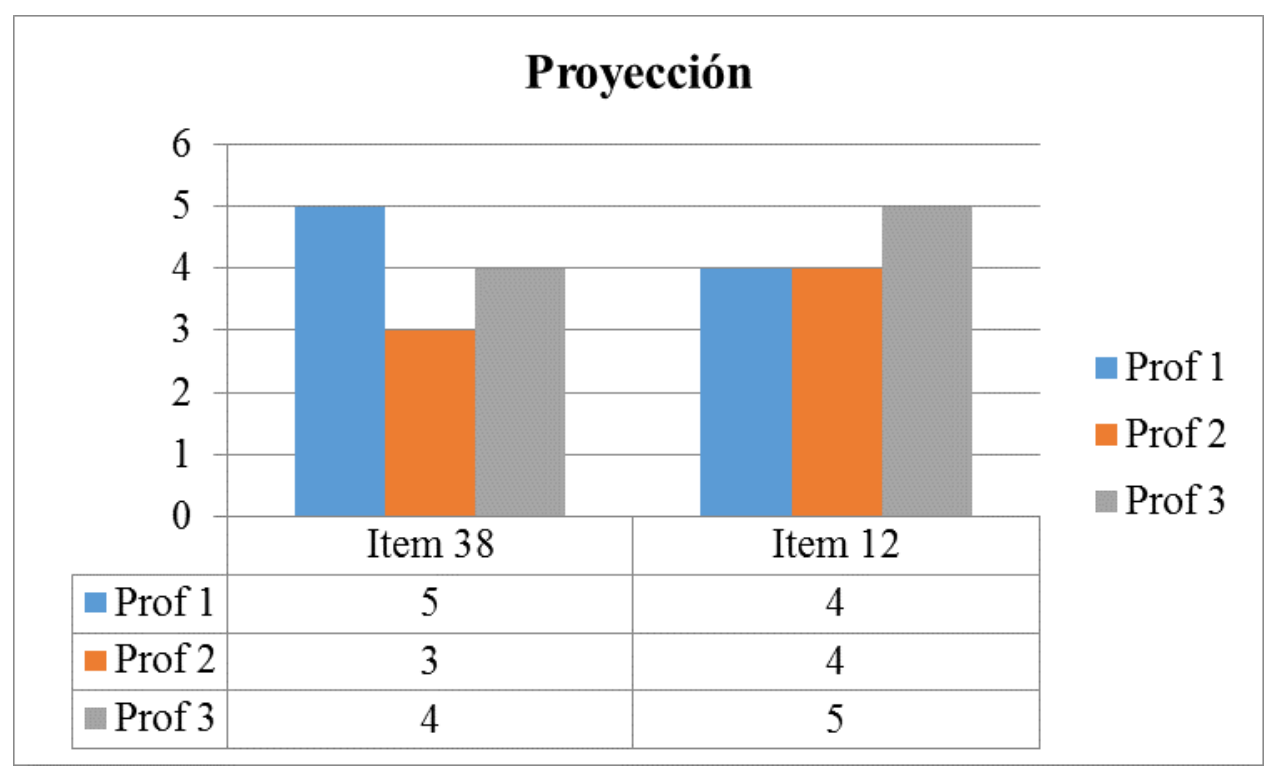

Gráfico 20: Resultados de la categoría Proyección en el profesorado por profesor.

Si analizamos los cuestionarios del profesorado individualmente, tenemos que los profesores 1 y 3 hacen una valoración general y particular positiva de la curación de contenidos y se han implicado más que el profesor 2.

Los profesores 1 y 3 valoran más que el 2 los aspectos metodológicos de la actividad y en cuanto a la proyección de la curación, sólo los profesores 1 y 2 valoraron la actividad con una proyección futura, aunque todos disponen de los medios necesarios para hacerlo.

\section{Discusión de los resultados}

Las herramientas de curación de contenidos más usadas en los tres grupos fueron, en función de la fase de curación, las siguientes: fase de búsqueda: Google (alertas); fase de curación: Pinterest, Scoop.it, Feddly; fase de difusión: Facebook, Twitter, Instagram.

Los aspectos en los que el alumnado refiere haber tenido más dificultad en función del grupo donde realizaron la curación son:

Los alumnos y alumnas, que realizaron la curación de contenidos con el profesor 1 y 3 , coincidieron al manifestar más dificultad en la comprensión de la práctica, entender la explicación del profesor, acordar el tema con el grupo, buscar/seleccionar contenidos para la curación, académicos y fiables, comprender los contenidos a curar, utilizar las distintas herramientas de curación, disponer de poco tiempo, lograr que todos los miembros del grupo se implicaran, difundir/divulgar los contenidos, utilizar las herramientas de divulgación, el idioma (inglés, en artículos, Scoop.it, ...), coordinación del grupo, sincronizar todas las redes sociales $\mathrm{y}$, algunos manifestaron no haber tenido ninguna dificultad.

Del grupo del profesor 2, mostraron tener más dificultad al buscar/seleccionar contenidos para la curación, encontrar contenidos académicos y fiables, utilizar las distintas herramientas de curación y algunos declararon no haber tenido ninguna dificultad. 
Tanto el alumnado como el profesorado valoran positivamente la curación de contenidos como estrategia didáctica general. Aquellos alumnos que realizaron la curación de contenidos con el profesor 2 , aunque también valoran positivamente la curación de contenidos de Psicobiología, lo hacen en menor medida que aquellos que lo hicieron con los profesores 1 y 3 . Téngase en cuenta que el profesor 2 , no valora positivamente la curación de contenidos en el área.

Los alumnos creen que, en general se han implicado los tres profesores aunque el profesor 2 admite no haberse comprometido y mantenido un rol activo en el desarrollo de las sesiones.

En relación a los aspectos metodológicos, los tres grupos dicen no haber participado lo suficiente en la actividad y no haber realizado antes curación de contenidos. Si consideran que las instrucciones, la forma de evaluar la actividad y el trabajo colaborativo como aspectos positivos de la curación de contenidos. Por su parte, el profesorado, a excepción del profesor 2, valoran positivamente los aspectos metodológicos.

En lo que se refiere a la proyección de la curación, tanto el profesorado como el alumnado creen que han progresado en la adquisición de sus competencias digitales y, disponen de los medios necesarios para seguir curando contenidos.

\section{Conclusiones}

Podemos decir que la curación de contenidos es una necesaria y nueva forma de acceder a la sociedad del conocimiento, filtrando la información web relativa a un tema, evitando la infoxicación y facilitando un mejor acceso a los contenidos, proporcionándoles un valor añadido para no ser simples agregadores de contenidos. El desarrollo de un entorno personal de aprendizaje a través de la curación de contenidos facilita la adquisición de objetivos y competencias del grado.

Es obvio que conocer la percepción que los participantes tienen respecto a dicha estrategia favorecerá el progreso en los que a las metodologías basadas en el aprendizaje en red, no solo a nivel universitario, sino también en otros niveles educativos.

En cuanto a los beneficios de la curación de contenidos como estrategia didáctica, los resultados sugieren que es necesaria una implicación activa por parte del profesorado para lograr los resultados esperados y que, es esencial la motivación y formación del profesorado en este sentido si queremos obtener resultados, razón por la que en sucesivas ocasiones se debería garantizar la formación específica delos profesores participantes.

Entendemos que en el futuro, la valoración positiva de este tipo de experiencias nos llevara a incluir la curación de contenidos en la oferta formativa del profesorado universitario, así como a conocer las insuficiencias y dificultades reales con las que se encuentra la universidad a la hora de trabajar las competencias informacionales en el ámbito universitario.

Coincidiendo con Negre, F., Marín, V. L. \& Pérez Garcias A. (2013), pensamos que en posteriores propuestas habría que concretar y definir las palabras clave en la fase de

Iniciación a la curación de contenidos en la universidad: una experiencia en el área de psicobiología. María José Romero Tirado. 
conceptualización, predeterminar los sistemas de búsqueda y filtrado a utilizar y convenir los criterios de selección de la información durante la valoración y selección de los contenidos. Por otra parte, sería de interés y conveniente establecer estrategias de colaboración con equipos docentes de otras universidades, así como con otras áreas afines en ulteriores implementaciones.

De todo lo anterior podemos deducir, coincidiendo con Zapata-Ros, (2014), sobre la necesidad de futuras líneas de investigación relacionadas con la curación de contenidos como estrategia didáctica basada en la web social que permitan profundizar en los contenidos, procesos de enseñanza y aprendizaje, gestión y tecnología.

Presentación del artículo: 30 de noviembre de 2015

Fecha de aprobación: 9 de marzo de 2016

Fecha de publicación: 30 de abril de 2016

Romero-Tirado, M.J. (2016). Iniciación a la curación de contenidos en la universidad: una experiencia en el área de psicobiología. RED. Revista de Educación a Distancia. 49(6). Consultado el (dd/mm/aaaa) en http://www.um.es/ead/red/49

\section{Referencias}

ANECA (2003): Programa de Convergencia Europea. El crédito europeo. Madrid: Agencia Nacional de Evaluación de la Calidad y Acreditación.

Badía, A. (2006). «Ayudar a aprender con tecnología en la educación superior». En A. Badía (coord.). Enseñanza y aprendizaje con TIC en la educación superior [monográfico en línea]. Revista de Universidad y Sociedad del Conocimiento (RUSC). Vol. 3, n. ${ }^{\circ} \quad 2 . \quad$ UOC. Recuperado de http://www.uoc.edu/rusc/3/2/dt/esp/badia.pdf.

Bhargava, R. (2009). Manifesto For The Content Curator: The Next Big Social Media Job Of The Future? En Influential Marketing Blog. Recuperado de http://rohitbhargava.typepad.com/weblog/ 2009/ 09/manifesto-for-the-contentcurator-the-next-big-social-media-job-of-the-future-.html.

Bhargava, R. (2011). The 5 Models of Content Curation. En Influential Marketing Blog. Recuperado de http://www.rohitbhargava.com/2011/03/the-5-models-of-contentcuration.html

Colas Bravo, M.P. \& Buendía Eximan, L. (1992) Investigación Educativa. Sevilla: Alfar.

Cornellá, A. (2008). Principio de la infoxicación. En J. J. Fernández (Ed.). Más allá de Google. Recuperado de www.infonomia.com/pdf/Mas_alla_de_Google_2008.pdf

Dcc.ac.uk,. (2015). What is digital curation? | Digital Curation Centre. Recuperado el 13 octubre de 2015, de http://www.dcc.ac.uk/digital-curation/what-digital-curation. 
De Benito, B., Darder, A., Lizana, A., Marín, V. I., Moreno, J. y Salinas, J. (2013). Agregación, filtrado y curación para la actualización docente. Píxel-Bit. Revista de Medios y Educación, 42, pp. 157-169.

González, A. T. (2012). La utilización de los blogs como recurso educativo en el área de Lengua Castellana y Literatura. Revista electrónica interuniversitaria de formación del profesorado, 15(4), pp. 127-137.

González, J. \& Wagenaar, R. (Coor.) (2003): TUNING. Educational Strutures in Europe. Bilbao: Universidad de Deusto.

Higgins, S. (2008). The DCC Curation Lifecycle Model. The International Journal of Digital Curation, 1(3). Recuperado de http://www.ijdc.net/index.php/ijdc/article/view/69.

Marín, V.; Moreno, J.; \& Negre, F. (2012). Modelos educativos para la gestión de la información en educación superior: Una experiencia de curación de contenidos como estrategia metodológica en el aula universitaria. EDUTEC, Revista Electrónica de Tecnología Educativa, 42. Recuperado de http://edutec.rediris.es/Revelec2/Revelec42/experiencia_curacion_contenidos_estrate gia_metodologica_aula_universitaria.html.

Marcelo, C. (2001). "Función docente: nuevas demandas para viejos propósitos», en: Marcelo, C. (coord.). La función docente. Madrid: Síntesis.

Morales, E. M., García, F. J., Barrón, Á., \& Gil, A. B. (2007). Gestión de Objetos de Aprendizaje de calidad: Caso de estudio. In Actas del IV Simposio Pluridisciplinar sobre Objetos y Diseños de Aprendizaje Apoyados en la Tecnología (pp. 19-21).

Negre, F., Marín, V. L. \& Pérez Garcias A. (2013). Estrategias para la adquisición de la competencia informacional en la formación inicial de profesorado de primaria. Revista electrónica interuniversitaria de formación del profesorado, 16 (2), pp. 1-12.

Onrubia, J. (2007). Las tecnologías de la información y la comunicación como instrumento de apoyo a la innovación de la docencia universitaria. Revista interuniversitaria de formación del profesorado, (58), pp. 21-36.

Salinas, J. (2008). Herramientas para la formación del profesorado. En F. Martínez (coord.): Incorporación de las TIC en los programas académicos de las universidades estatales costarricenses. (pp. 69-88). Murcia: Diego Marín.

Zapata-Ros, M. (2014). Gestión del aprendizaje en Educación Superior y web social. RED, Revista de Educación a Distancia, 42. Recuperado de http://www.um.es/ead/red/42.

Iniciación a la curación de contenidos en la universidad: una experiencia en el área de psicobiología. María José Romero Tirado. 


\section{Cuestionario de alumnos:}

Iniciación a la curación de contenidos en la universidad: una experiencia en el área de Psicobiología

Nombre del profesor/a/es encargado/a/os/as de realizar la práctica 3:

Turno:

Grupo reducido:

Este cuestionario intenta recabar información sobre distintos aspectos relativos al proceso de aprendizaje de la práctica, iniciación a la curación de contenidos en el área de Psicobiología. Con el fin de conocer, mejorar y adaptar dicha actividad, nos gustaría y agradecemos enormemente, que cumplimente el siguiente cuestionario con carácter anónimo y cuya información será tratada de forma confidencial.

Cada declaración contiene cinco posibles respuestas, a saber:

(1)Totalmente en desacuerdo $: ;$

(2) En desacuerdo : :

(3) Ni de acuerdo ni en desacuerdo $\odot$

(4) De acuerdo $\odot$

(5) Totalmente de acuerdo $;$; $;$

En relación a la actividad en la que os habéis iniciado en curación de contenidos, conteste marcando con una $\mathrm{X}$ en la casilla correspondiente, la opción que mejor se ajuste a su opinión y/o percepción de dicha actividad práctica:

\begin{tabular}{|c|c|c|c|c|c|}
\hline & : & : & :) & (;) & $+;$ \\
\hline & 1 & 2 & 3 & 4 & 5 \\
\hline $\begin{array}{l}\text { 1. Considero que se trata de una actividad muy apropiada } \\
\text { para fomentar el trabajo en equipo/colaborativo }\end{array}$ & & & & & \\
\hline 2. Pienso que es una práctica motivadora en general & & & & & \\
\hline $\begin{array}{l}\text { 3. El profesorado se ha encargado de instruir y dinamizar } \\
\text { la actividad }\end{array}$ & & & & & \\
\hline $\begin{array}{l}\text { 4. Las instrucciones publicadas a través de la plataforma } \\
\text { virtual son claras y explicitas respecto a la actividad }\end{array}$ & & & & & \\
\hline
\end{tabular}

Iniciación a la curación de contenidos en la universidad: una experiencia en el área de psicobiología. María José Romero Tirado. 


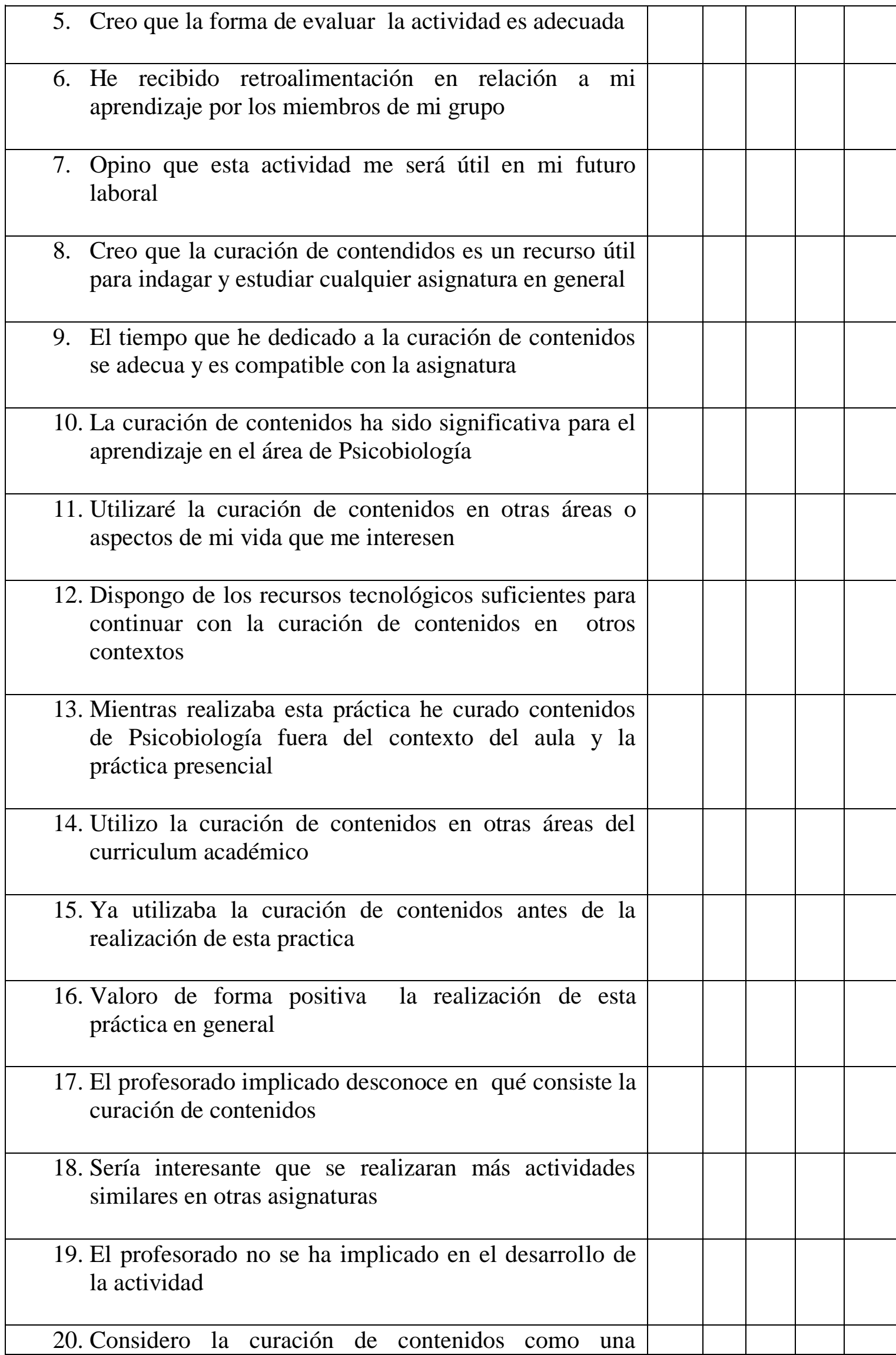




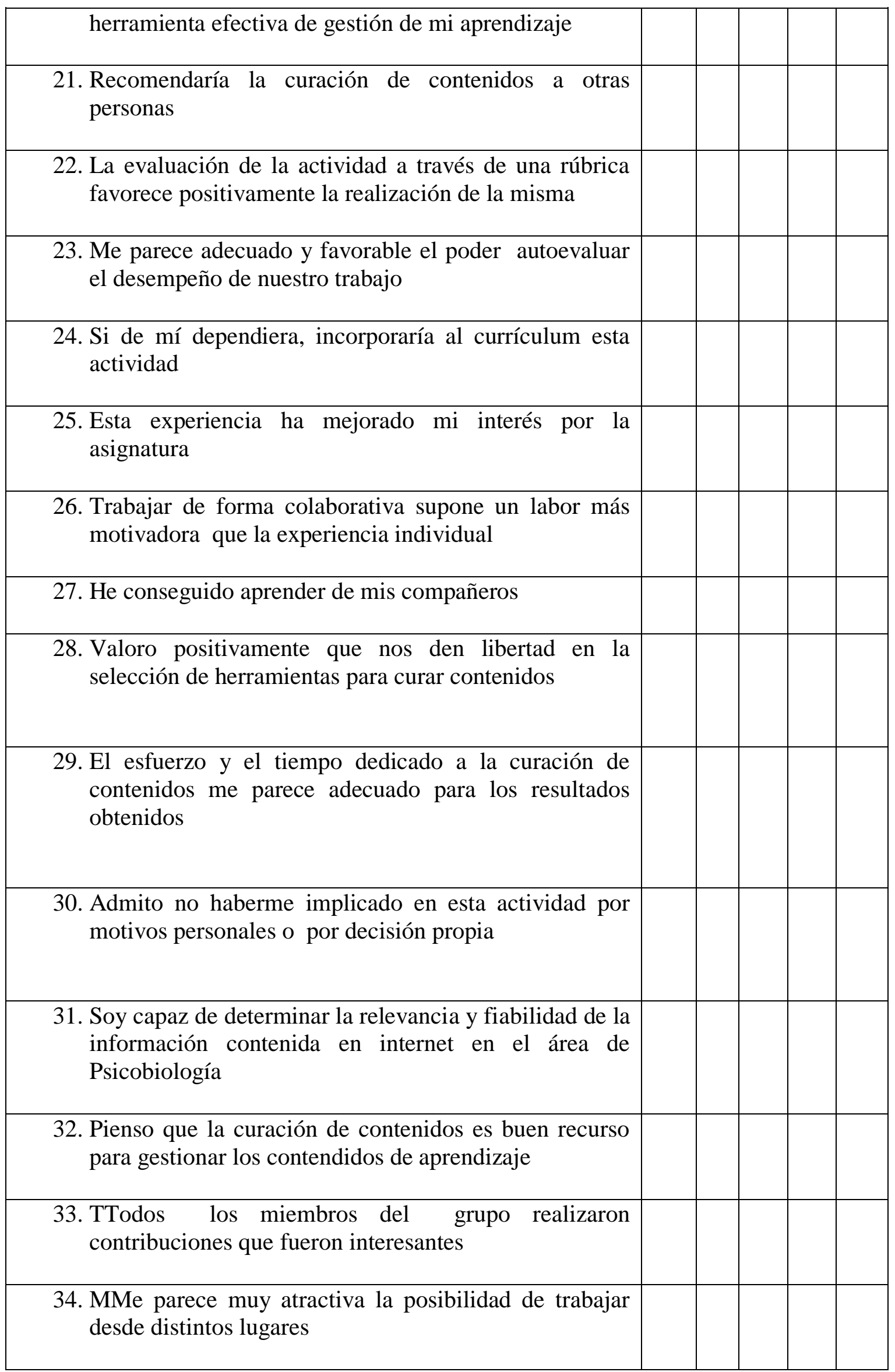




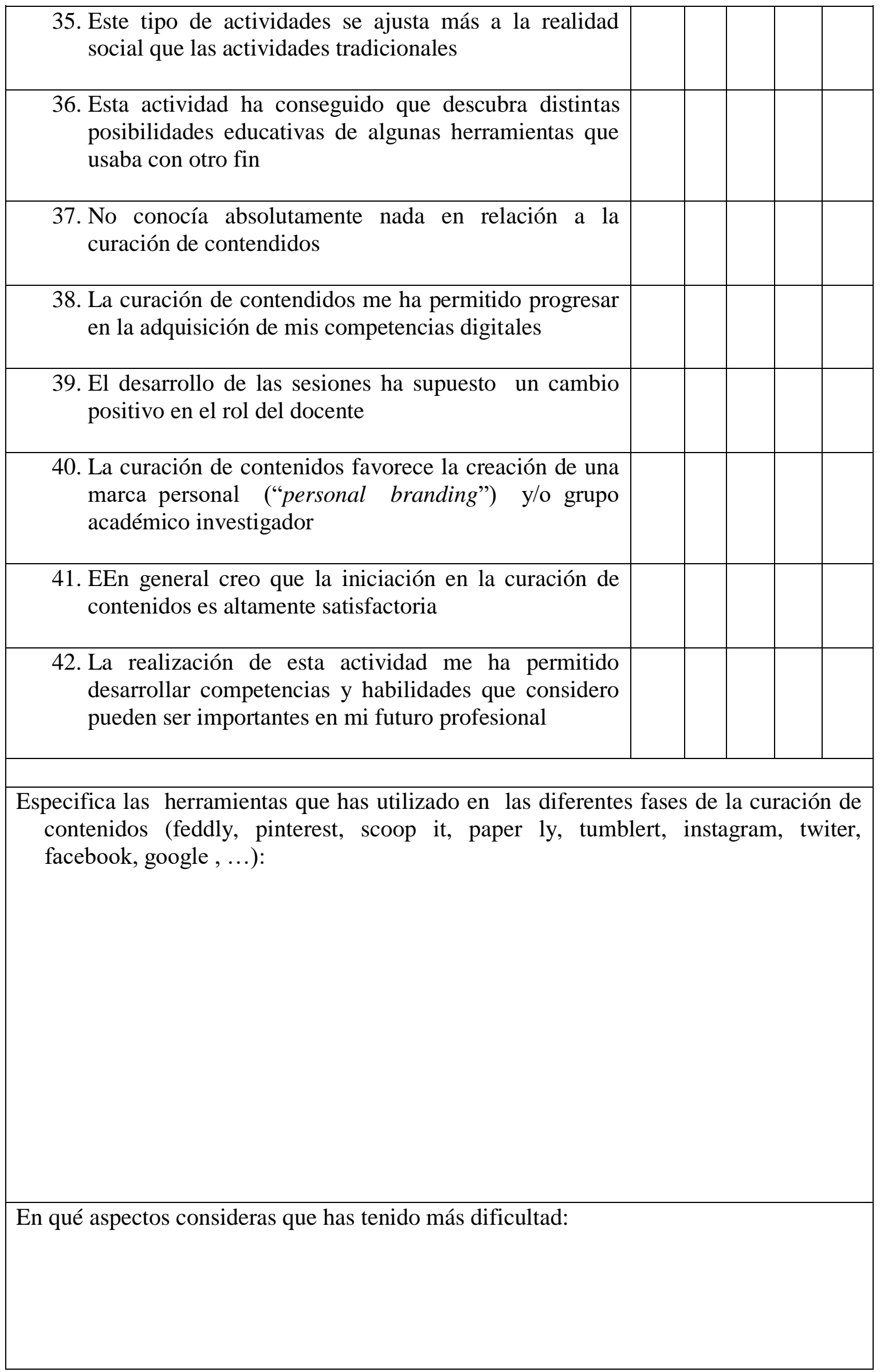

Iniciación a la curación de contenidos en la universidad: una experiencia en el área de psicobiología. María José Romero Tirado. 
En qué aspectos has tenidos menos dificultad:

Qué cambiarias en un futuro para mejorar esta actividad:

\section{Observaciones:}




\section{Cuestionario de profesores}

Iniciación a la curación de contenidos en la universidad: una experiencia en el área de Psicobiología

Nombre del profesor/a/es encargado/a/os/as de realizar la práctica 3:

Turno:

Grupo-s reducido-s:

Este cuestionario intenta recabar información sobre distintos aspectos relativos al proceso de aprendizaje de la práctica, iniciación a la curación de contenidos en el área de Psicobiología. Con el fin de conocer, mejorar y adaptar dicha actividad, nos gustaría y agradecemos enormemente, que cumplimente el siguiente cuestionario con carácter anónimo y cuya información será tratada de forma confidencial.

Cada declaración contiene cinco posibles respuestas, a saber:

(1)Totalmente en desacuerdo $: ;$

(2) En desacuerdo : :

(3) Ni de acuerdo ni en desacuerdo $\odot$

(4) De acuerdo $\odot$

(5) Totalmente de acuerdo $;$; $;$

En relación a la actividad práctica de curación de contenidos, conteste marcando con una $\mathrm{X}$ en la casilla correspondiente, la opción que mejor se ajuste a su opinión y/o percepción de dicha actividad práctica:

\begin{tabular}{|c|c|c|c|c|c|}
\hline & 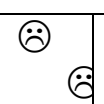 & $:$ & :) & (:) & (:) \\
\hline & 1 & 2 & 3 & 4 & 5 \\
\hline $\begin{array}{l}\text { 1. Considero que se trata de una actividad muy apropiada } \\
\text { para fomentar el trabajo en equipo/colaborativo }\end{array}$ & & & & & \\
\hline 2. Pienso que es una práctica motivadora en general & & & & & \\
\hline $\begin{array}{l}\text { 3. El profesorado se ha encargado de instruir y dinamizar } \\
\text { la actividad }\end{array}$ & & & & & \\
\hline $\begin{array}{l}\text { 4. Las instrucciones publicadas a través de la plataforma } \\
\text { virtual fueron claras y explicitas respecto a la actividad }\end{array}$ & & & & & \\
\hline 5. Creo que la forma en que se evaluó la actividad es & & & & & \\
\hline
\end{tabular}

Iniciación a la curación de contenidos en la universidad: una experiencia en el área de psicobiología. María José Romero Tirado. 


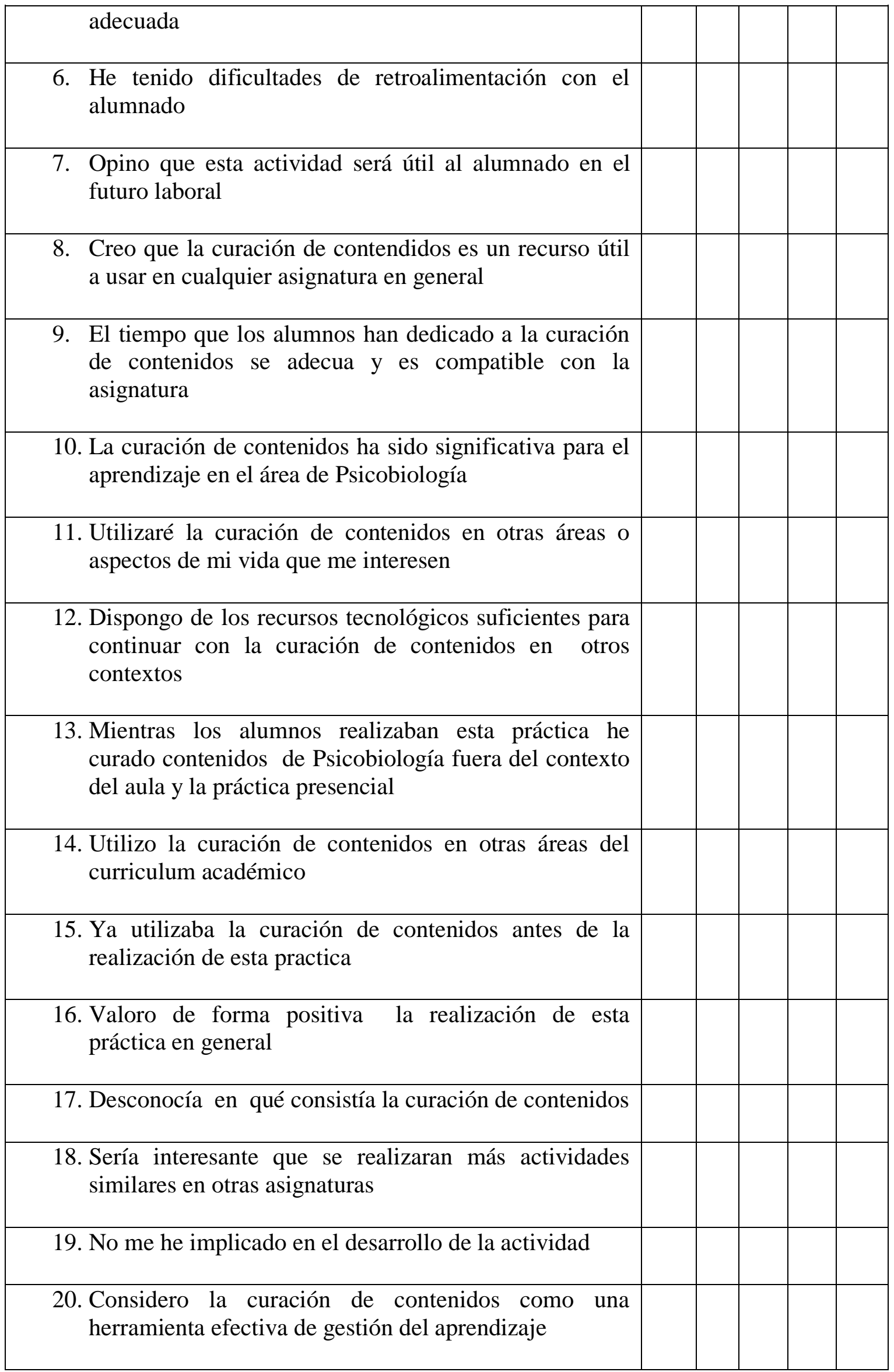




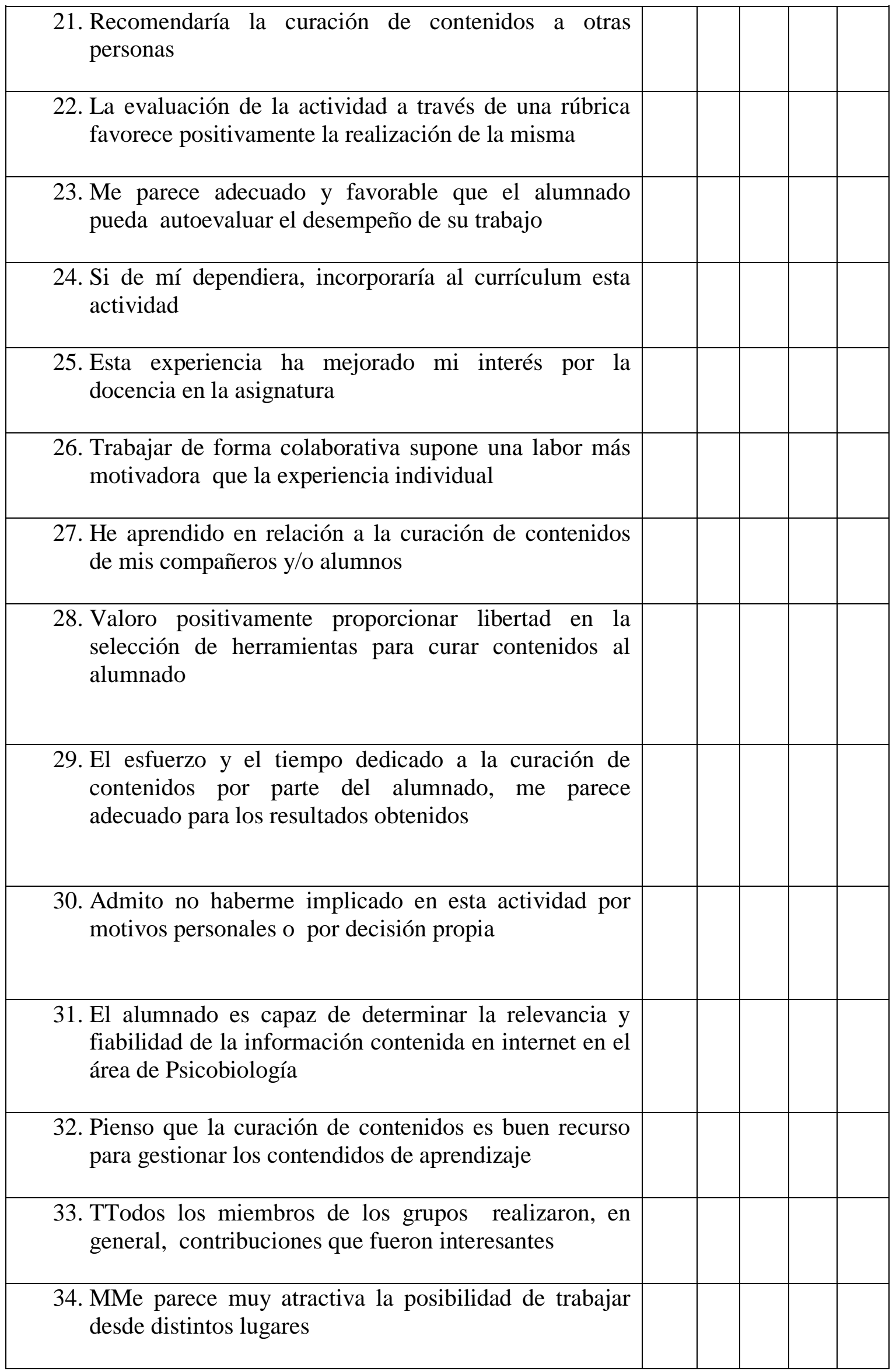




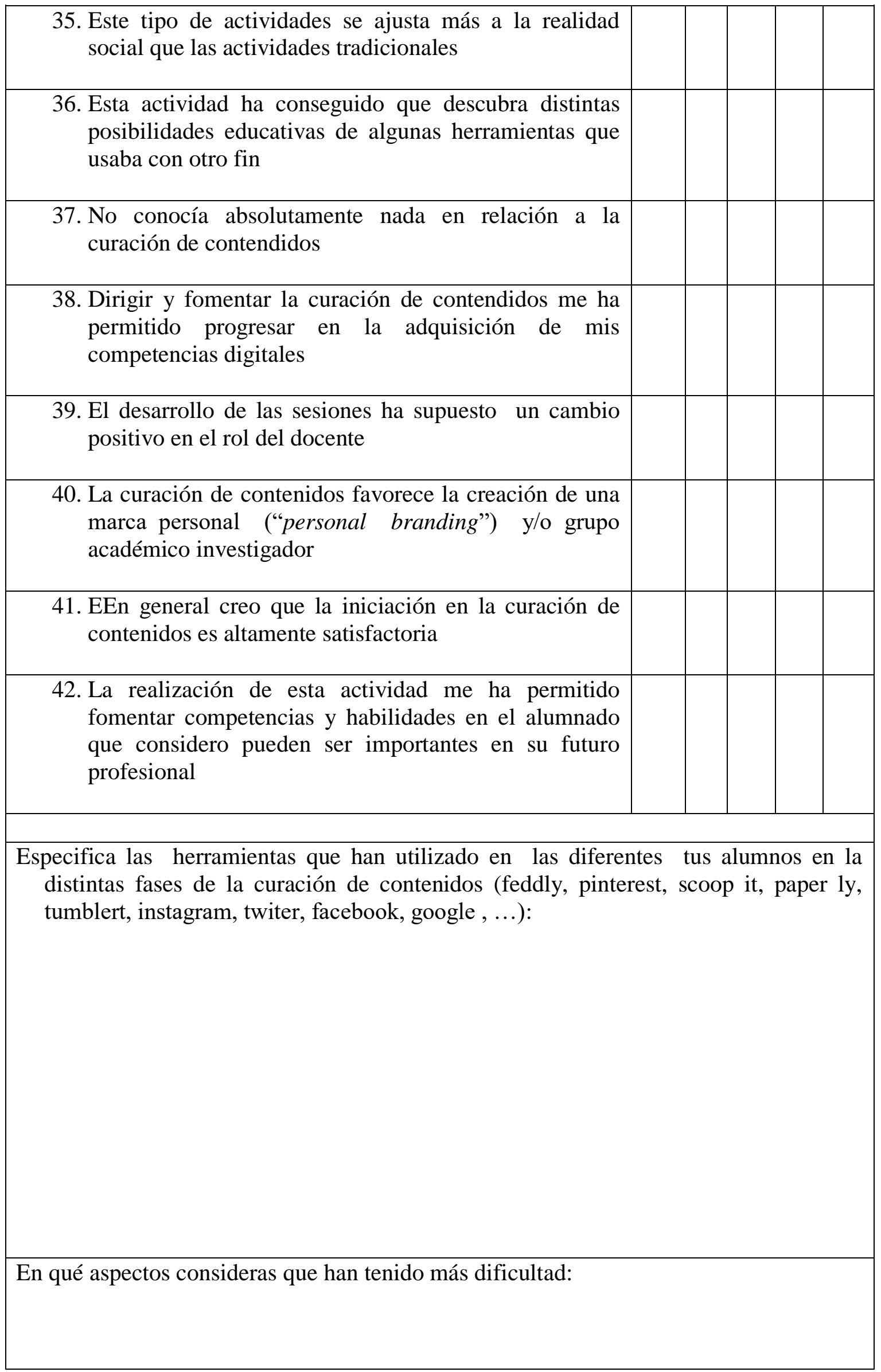


En qué aspectos han tenido menos dificultad:

Qué cambiarias en un futuro para mejorar esta actividad:

Observaciones:

Iniciación a la curación de contenidos en la universidad: una experiencia en el área de psicobiología. María José Romero Tirado. 